\title{
Sharing economy research in hospitality and tourism: a critical review using bibliometric analysis, content analysis and a quantitative systematic literature review Mody, M. and Cheng, M. and Hanks, L.
}

\begin{abstract}
Purpose - This study conducts a critical review of the research on the sharing economy to identify its key intellectual foundations and their evolution and offers thematic and methodological recommendations for future research to advance the domain.

Design/methodology/approach - A tri-method approach using bibliometric (co-citation) analysis, thematic content analysis, and a quantitative systematic literature review was conducted on sharing economy research in hospitality and tourism journals, up to and including May 2020. Findings - The findings from the three methods were coherent and provide a clear picture of the fact that while research on the sharing economy in hospitality and tourism has achieved significant depth, the breadth of our understanding of this area remains somewhat limited. Each of the three periods of research on the sharing economy identified in the study were marked by a focus on specific thematic areas, with largely Western-situated researchers demonstrating limited theoretical engagement and employing a limited range of methods and perspectives (disciplinary, stakeholders, sectors) to examine these themes.

Research limitations/implications - Recommendations for future thematic research opportunities are provided using a multi-level perspective (MLP). The present review does not include research that incorporates the impacts of COVID-19, which has significantly disrupted the hospitality and tourism industry and is the focus of current research in the field. However, the review represents the largest and most comprehensive assessment of the state of research on the sharing economy prior to COVID-19, and, as such, can serve as a valuable baseline for future reviews of sharing economy research during and after the pandemic.

Originality/value - In contrast with previous literature reviews, the present review is comprehensive in its scope, methodology, and temporal coverage of sharing economy research. It also examines the evolution of research on the topic, enabling a more nuanced identification of gaps and future thematic and methodological research opportunities.
\end{abstract}


Keywords Literature review, sharing economy, peer-to-peer platforms, Airbnb, bibliometric analysis

Paper Type Literature review

\section{Introduction}

The sharing economy, a term that entered common parlance around the recession of 2008, refers to an economic or business model that leverages information technology to facilitate the sharing of goods and services between individuals (Wirtz et al., 2019). The exponential growth of the sharing economy has been accompanied by a proliferation of academic research on the topic across different disciplines, including hospitality and tourism. Indeed, the quantity of research output has prompted several researchers to conduct reviews of the literature on the sharing economy in hospitality and tourism (e.g., Altinay and Taheri, 2019; Sainaghi and Baggio, 2020).

While these reviews have provided important understanding of the theoretical, methodological, and topic-oriented developments in the body of research on the sharing economy, some notable gaps exist in the literature. First, most reviews tend to focus only on accommodation platforms (and in some cases, only on Airbnb) that comprise the sharing economy, ignoring other sectors (e.g., Kuhzady et al., 2020; Sainaghi, 2020). Second, extant reviews tend to rely solely on a single method to review the literature (e.g., Prayag and Ozanne, 2018; Guttentag, 2019), despite the availability of a variety of methodological approaches to conducting literature reviews. This limits both the nature and scope and also the validity and reliability of the findings of extant reviews. Third, extant reviews tend to be limited in their temporal scope, and do not capture the most recent proliferation of research on the sharing economy (Sainaghi, Köseoglu and Mehraliyev, 2020; Sainaghi, Köseoglu, Angella, et al., 2020). 


\section{Fourth, some reviews (e.g., Hossain, 2020) focus on sharing economy literature from multiple} disciplines, thus not being able to identify the needs and requirements of hospitality and tourism in particular.

The unique contribution of the current study is that it addresses these shortcomings by adopting a tri-method approach to a critical review of the sharing economy literature in hospitality and tourism, up to and including May 2020, using bibliometric (co-citation) analysis, thematic content analysis, and a quantitative systematic literature review (Cheng et al., 2018). These three methods complement and supplement each other in enabling a nuanced and holistic assessment of the sharing economy literature. We adopt Wirtz et al.'s (2019) definition of the sharing economy as business models that enable the peer-to-peer (P2P) sharing (as opposed to transfer of ownership) of capacity-constrained assets and resources (such as accommodation, transportation, and experiences, and excluding capacity-unconstrained resources such as files, music, information, etc.) in hospitality and tourism. Thus, these business models exclude platforms that enable the sharing of marketer-provided resources that may be used for the purpose of hospitality and tourism; e.g., Zipcar supplies the cars that are used by customers of the platform (marketer-provided assets), but, in the case of Airbnb, the company itself does not supply any accommodation (peer-provided assets). Moreover, by focusing our review on the literature published only in hospitality and tourism journals, our review is tailored to address the theoretical, methodological, and thematic specificities of the field.

The main contribution of our three-method critical review is that it establishes the temporal evolution of the key intellectual foundations of research on the sharing economy in hospitality and tourism, and, in so doing, identifies the resulting gaps and opportunities for future research. We structure the thematic opportunities for future research using the multi-level 
perspective (MLP) while also providing methodological considerations for future researchers in the domain. Overall, these opportunities reflect our observation that while research on the sharing economy in hospitality and tourism has achieved significant depth, the breadth of understanding of this area remains somewhat limited. Moreover, researchers embarking on this area are encouraged to adopt methodological approaches that allow for the development of theory that is emic to the sharing economy in hospitality and tourism, as opposed to focusing solely on the application of existing disciplinary frameworks.

\section{Literature review}

\subsection{The history of the sharing economy}

Generally speaking, the sharing economy comprises online platforms that facilitate the sharing between peers of assets or services that are underutilized (Wirtz et al., 2019). Over the past decade, the sharing economy has grown exponentially, and the industry is predicted to be worth $\$ 335$ billion by 2025 (Prayag and Ozanne, 2018). The sharing economy is differentiated from more traditional economic models in that assets are shared not by a company, but rather directly between stakeholders, who have direct contact with each other. The advent of the sharing economy, in its current form, can be traced to the launch of eBay in 1995 (Belyh, 2019). Since that time, it has seen remarkable growth, particularly in the domains of accommodation, transportation, and finance (Ranjbari et al., 2020). Participation in the sharing economy benefits the host or owner, in that it allows them to increase the return on their investment in the asset by lending it to others, most often for a fee. For the consumer, it allows access to goods and services without the cost of purchase (Belarmino and Koh, 2020). 
In the last two decades, there has been a significant expansion in the ridesharing and accommodation sectors of the sharing economy, which are of particular relevance to hospitality and tourism researchers. The founding of VRBO (1995), HomeAway (2005), Airbnb (2008), Uber (2009), and Lyft (2012), among many others, has attracted the attention of researchers, as these sharing companies represent a radical departure from the typical business model of the hospitality industry. Since 2010 , there has been unprecedented growth in the scholarly literature regarding the sharing economy.

\subsection{Previous literature reviews on the sharing economy}

The proliferation of academic research on the sharing economy in hospitality and tourism has been accompanied by several review studies that capture the state of the literature on the topic. Here, we refer to studies that review academic research on the sharing economy, and exclude those that review non-academic discourse on the topic (Cheng, 2016a). We present these key academic review studies in Table 1, including their key findings and limitations in terms of scope, method, or the duration/recency of the reviewed research.

\section{Insert Table 1 here}

The first of these review studies was published in 2016 by Cheng (2016b), who examined 66 publications on the sharing economy, with only ten of those related to hospitality and tourism. This was followed by Heo's (2016) review study, which was not empirical in nature; rather, it was based on a discussion of selective academic discourse on the sharing economy. Following these two early studies, as academic research on the topic proliferated, researchers began to use 
larger and more updated datasets to examine the state of sharing economy literature. For example, Prayag and Ozanne (2018) examined research between 2010 and 2016 and adopted a multi-level perspective (MLP) to systematically review literature on P2P accommodation. Review studies published in 2019 (e.g., Dann et al., 2019) also largely attempted to capture the state of research pertaining to Airbnb, while ignoring other sectors of the sharing economy. While Altinay and Taheri's (2019) study was an exception to this rule, their methodological approach was based on a convenience sample of studies that emphasized the application of nine major theories (e.g., complexity theory, social exchange theory, etc.) and seven themes (e.g., trust and reputation, pricing strategies, etc.) to sharing economy research in hospitality and tourism, thus limiting its comprehensiveness.

The year 2020 witnessed the addition of six major review studies (see Table 1), which are indispensable to understanding the "intellectual structure" of research on the sharing economy (Sainaghi, Köseoglu and Mehraliyev, 2020). However, as with the previous reviews, these studies collectively represent four notable issues. First, the scope of most reviews tends to be limited to $\mathrm{P} 2 \mathrm{P}$ accommodation platforms. While this is reflective of the fact that $\mathrm{P} 2 \mathrm{P}$ accommodation (and Airbnb) has indeed garnered the most research attention, it excludes evidence from other sectors of the sharing economy. These other sectors are not only highly relevant to understanding hospitality and tourism phenomena—for example, tourists may use Uber at a destination, which may influence their perception of the overall experience of the destination — but may also represent a more significant economic component of the sharing economy (e.g., Airbnb's estimated revenue for 2019 is $\$ 4.7$ billion, while that for Uber is $\$ 14.1$ billion). 
Second, a critical review of the state of the literature on a topic can be constructed using a variety of approaches and methods, each of which has its own pros and cons and can offer a different and unique perspective to understanding the topic (Kim et al., 2018). However, extant reviews of the literature on the sharing economy tend to rely on a single, or, at best, two methodological approaches. For example, while Sainaghi and colleagues published four review studies on the sharing economy in 2020, three of these studies relied on a single method only (co-citation analysis or systematic literature review). Likewise, Kuhzady et al. (2020) used only text analysis to categorize articles and topics.

Third, the most updated review of research on the sharing economy has been conducted up to October 2019 (Kuhzady et al., 2020), while all other reviews exclude the large amount of important research that has been conducted in 2019 and 2020. Relatedly, while aggregating sharing economy research over the timespan of the review, extant reviews do not examine the temporal evolution of this research i.e., how the topics and themes examined in sharing economy research have evolved over time. While Kuhzady et al.'s (2020) study is an exception to this rule, they divided the timespan of their review into two distinct phases, in contrast with a more continuous evolution of sharing economy research examined in the present study. A continuous evolution allows researchers to more precisely identify how the nature of inquiry about the sharing economy has unfolded over time and to identify opportunities for future research that advance knowledge in this domain. Fourth, some reviews, such as that by Hossain (2020), examine the sharing economy literature in multiple disciplines, including research in the areas of policy, marketing, information systems, and sustainability. While relevant and important, such reviews do not adequately illuminate the state of sharing economy research specifically in the domain of hospitality and tourism. 
The present study thus addresses the need for a more comprehensive, nuanced, holistic, and updated review of the state of the hospitality and tourism literature on the sharing economy, and seeks to address the following research questions:

RQ 1. What are the key intellectual foundations of the research on the sharing economy in hospitality and tourism? How have these key foundations evolved over time?

RQ 2. What are the available future research opportunities - thematic and methodological — in the domain of the sharing economy in hospitality and tourism?

\section{Research design}

\subsection{Article selection}

In order to capture all relevant research examining the sharing economy in hospitality and tourism, a list of keywords was used to search for articles in the largest scholarly database, Scopus, through titles, keywords, and abstract. The key terms include both general terms (e.g., peer-to-peer accommodation, sharing economy) and specific brand names (e.g., Airbnb and Uber), and are included in the flowchart in Figure 1. To narrow the scope of the review, only articles published in hospitality and tourism journals in English from 2010 to May 2020 were included. While some literature reviews focus only on papers published in leading hospitality and tourism journals, research on the sharing economy is not limited to leading journals, as noted by Dolnicar (2019); thus, focusing only on select leading outlets may lead to the exclusion of highly relevant research that characterizes the domain of the sharing economy.

After generating the initial list of studies, three researchers examined all the articles in their entirety and retained only those which had the sharing economy as their main focus, for a total of 308 articles. 82 articles were excluded from the initial search based on the following 
criteria: 1) they misused the definition of the sharing economy; or 2) they mentioned one or more of the keywords but the article pertained to another topic; or 3) they mentioned the sharing economy as part of the article, but the discussion of it in the paper was minor. As an example of an article excluded based on the third criteria, Alrawadieh et al. (2020) identify in the abstract and manuscript of their study that disruptive business models like Airbnb pose a threat to the market share of the traditional lodging industry; however, there is no discussion of the sharing economy beyond that, and the main focus of the article is on the benefits of digital transformation of revenue management practices in the hotel industry. For all 82 articles, all three researchers unanimously agreed to their exclusion.

\section{Insert Figure 1 here}

The key information about these articles retrieved from Scopus included the citation information of author(s), document title, year, source title, citation count, source, document type, and DOI; author affiliations, abstract, keywords; content of full-length article; and references. A full list of articles identified in this critical review are included in the supplementary data file.

\subsection{Data analysis}

Following the recommendations of Cheng et al.'s (2018) review of the literature on adventure tourism, a tri-method approach to performing a critical review of sharing economy research was employed, involving bibliometric (co-citation) analysis, thematic content analysis, and a quantitative systematic review. The rationale to adopting this approach is that the three methods "complement each other in a holistic, objective, and accountable manner that helps reduce the 
bias that is often related to traditional literature reviews and expert interviews" (p. 998). Cocitation analysis provides a clear demonstration of the structure and theoretical foundations of the sharing economy literature. The method was developed in the early 1970s and uses the frequency of two publications cited in pair to infer how the focal articles are built through its theoretical foundation and disciplinary traditions. Content analysis is either a manual or automated method that provides a text-driven review of articles to make valid inferences about key thematic areas pertaining to a topic.

A quantitative systematic literature review makes possible the synthesis of a large and diverse body of research that has been conducted using varying contexts and methods. Such systematization allows for the discovery of patterns and the identification of under-researched areas within a specific topic. A systematic review uses search criteria that are clearly defined and methods that are replicable in order to select and examine extant research studies (Pickering and Byrne, 2014). A detailed explanation of these three methods can be found in Cheng et al. (2018).

In the present study, for the co-citation analysis, all the articles with full references obtained from Scopus were analyzed using CiteSpace. The co-citation network was visualized using the software Gephi. It is important to note that co-citation is not aimed at identifying the relationship between focal articles, but rather the references of the focal articles and how the references appear together in pairs. The results of the co-citation analysis are presented in Figures 2 and 3 . The dots and their base relationship along with the timeline in the visualized figure indicate the intellectual foundations and structure of the sharing economy during different time periods. Each color represents one core foundational area. It is important to note that if two foundational areas are connected by lines, they are related, co-foundational areas. The relative size of a dot represents its importance in its foundation area. 
For the thematic content analysis, word occurrence based on the abstract was performed along with the articles' publication timelines. Content analysis was first performed by using CiteSpace to generate the evolution of sharing economy research in hospitality and tourism, along with the timeline, through co-word analysis. The word analysis is based on the keywords in the selected articles, which reflect the salient information contained in them. These keywords are clustered based on their frequency of co-occurrence. The keywords that appear more often will be closely connected. The clusters along the timeline are labeled by the keyword with the highest value in centrality in its respective cluster. The number of the cluster also reflect its importance — starting with \#0, which indicates highest importance (Chen, 2014). After generating the visualized map, as suggested by the literature, the researchers examined the keywords appearing in the associated articles to provide the network-based interpretation. The word bubble in the visualized figure (Figure 4), derived from the content analysis, represents the key thematic areas researched in a certain period. The line between word bubbles indicates the relationship between thematic areas.

For the quantitative systematic literature review, each article was examined individually by the researchers, and information was extracted and cataloged in a number of categories, including: country and continent of author/institution affiliation, type of article (e.g., full article/research note), nature of research (e.g., empirical/conceptual), disciplinary approach, sharing economy sector, focal stakeholder(s), research method, data collection method, analysis method, sample description and sample size, country and continent of research, theoretical framework employed, key outcome variables, and the key findings and the limitations of the research study, which were also used to derive the opportunities for future research. The coding for each column was cross-examined by two researchers and refined until agreement was 
reached. A series of pivot tables was run on the data using Microsoft Excel. Analysis was run on each category of data, mapped against the year of publication, in order to identify trends, patterns, and changes in the hospitality and tourism literature on the sharing economy. Moreover, our analysis of the key categories along the timeline of our data collection mirrors the co-citation and thematic content analyses in which the evolution of the key intellectual foundations of the sharing economy research was examined.

\section{Results}

An analysis of the articles published during the review period indicated that research on the sharing economy in the hospitality and tourism literature has increased significantly over time, and particularly since 2016. As indicated in Table 2, in 2016, there were nine articles published on the topic, a number which subsequently increased to 33 articles in 2017, 51 articles in 2018, 123 articles in 2019 (a 141\% growth rate over 2018), and 83 articles in the first five months of 2020. These results are indicative of not only the increased availability of data on the sharing economy, but also the increased importance and relevance of sharing economy research to the academic community.

Our results also indicated that the distribution of academic research on the sharing economy in hospitality and tourism is highly concentrated, with over half $(56 \%)$ of the total output coming from five journals. The International Journal of Contemporary Hospitality Management (IJCHM) spearheaded the proliferation of research on the topic in its early days, with 16 papers published in 2017 alone. Since then, IJCHM has continued to be a leader in this area of research, joined in subsequent years by the International Journal of Hospitality Management (IJHM) (which published 26 papers in 2019 alone) and Current Issues in Tourism. 
Insert Table 2 here

\subsection{Bibliometric (co-citation) analysis}

The co-citation network is presented in Figure 2. The Louvain algorithm resulted in six clusters in the co-citation network. There are 129 references co-cited together with 4,161 connections. Each cluster is represented by a different color. The co-citation network resulted in a highly centralized network, which indicates the inter-dependence of the scholarly streams that have coinfluenced the development of the sharing economy literature. These scholarly streams include psychological and economic perspectives from the general consumer behaviour literature (e.g., psychological engagement), a general business perspective (e.g., consumption practices), a hotel revenue assessment perspective (e.g., hotel revenue), and impact perspectives. While these psychological and economic perspectives have provided a significant foundation to advance the sharing economy literature, they provide a relatively narrow understanding of the phenomenon. They also indicate opportunities to embrace other perspectives that could possibly diversify and broaden our understanding of the sharing economy, such as cross-cultural theories and sustainable livelihood perspectives.

Insert Figure 2 here

Insert Figure 3 here 
In addition to identifying the clusters and the relationships between them, we also map the temporal evolution of the key intellectual foundations of the sharing economy literature to examine how the nature of research on the topic has progressed. As evident in Figure 3, Cluster 0 (host-guest interaction) was the foundation of the early work on the sharing economy in hospitality and tourism journals, between 2012 and 2014-2015. This first period of research highlights the alternative experience provided by these new sharing economy businesses, which enable a new type of host-guest interaction. Research from 2014-2015 onwards has been built on multiple foundations. The shift to multiple clusters indicates that the investigation of the sharing economy became more diverse than in the early phase of the first period. It clearly indicates the shift in focus from the host-guest interaction (Cluster 0) to the role of the sharing economy (Clusters 7 and 8), the differences between traditional accommodation providers and Airbnb (Cluster 10), and the sharing economy's economic impacts, psychological engagement, and value co-destruction (Clusters 1 and 4).

The second period of research built on the foundations of the mainstream business literature on the sharing economy, discussing the disruptive role of sharing economy models, including clusters 7 (informal sector), 8 (engagement platform) and 14 (individual seller). The third period of research (most recent years) rests on the dominant foundation of traditional literature in consumer psychology and sociological theories (cluster 4-value condestruction/creation, 5-repurchase intention and 6-social presence). This period also witnessed a number of studies leveraging traditional hotel research domains, such as revenue management. Notably, the recent years also proliferated studies that built on the foundation of earlier research published in hospitality and tourism journals (e.g., Tussyadiah, Mody and their colleagues), marking a stage of rapid growth of the sharing economy literature in the field. 


\subsection{Thematic content analysis}

Figure 4 presents the results of the thematic content analysis mapped against the timeline of publication.

\section{Insert Figure 4 here}

In early 2010, Couchsurfing was the main focus of the sharing economy literature, highlighting its critical role in providing a hospitality experience alternative to mainstream accommodation providers. Using a sociological and cultural perspective, Germann Molz (2012) highlights how the sharing economy, through CouchSurfing, changed the way hospitality is performed. Beginning in 2016, more discussions examined the boundaries of the sharing economy whilst examining the disruptive nature of its alternative experience provision, particularly in the P2P accommodation context. The study by Guttentag (2015) is perhaps the most cited article on the sharing economy. Underpinned by disruptive innovation theory, Guttentag (2015) pointed out that the rapid rise of Airbnb and its novel business model presents a distinct appeal but also imposes significant potential legal challenges.

This period (2015/2016 onwards) saw the emergence of various topics centered on the sharing economy provider's implications for tourism destinations (e.g., increased length of stay and activities in the destination: Tussyadiah and Pesonen, 2015), the hotel industry (Gutierrez et al., 2017), and the tourism market (e.g., segmentation and expectation of using Airbnb: (Guttentag et al., 2018). Airbnb dominated research during this period. A majority of research between 2016 and 2018 was focused on the customer experience of the sharing economy, with trust an important construct that is considered essential to the peer-to-peer premise of the sharing 
economy. For example, Wu et al. (2017) identified a variety of host attributes that help build trust with potential renters and subsequently drive their purchase of short-term rentals. Regulation also emerged as an issue but was not examined in great depth, in particular empirically.

The topics concerning the sharing economy became more diverse in 2019 and 2020. Online reviews as a source of data to investigate sharing economy phenomena became increasingly popular, with topics ranging from identifying service quality criteria to various travel behaviour (Cheng and Jin, 2019; Zhu et al., 2019). In particular, researchers have linked the insights identified in online reviews to booking intentions and loyalty (Cheng and Jin, 2019) and to user satisfaction (Zhu et al., 2020). The impact of Airbnb on the short-term rental sector, housing market, and the hotel industry has also been extensively investigated in the last two years, highlighting that Airbnb as the poster-child of the sharing economy has reached a stage where its impacts have grabbed the attention of society at large (Dann et al., 2019).

Some topics that have been ignored in the hospitality and tourism also emerged from the thematic content analysis; these included the issue of sustainability (Cheng, Chen, et al., 2020), consumption authenticity (Mody and Hanks, 2019), specific economic impacts (e.g., employment effects: (Dogru, Mody, Suess, McGinley, et al., 2020), and the use of social media data as a data source. While these topics have begun to emerge in the literature, there is still a significant scope for research into these areas, as further established by the findings of the quantitative systematic literature review. 


\subsection{Quantitative systematic literature review}

In addition to the key intellectual foundations and thematic areas identified via the co-citation and content analyses, our systematic literature review pointed to a number of important ontological and epistemological trends in sharing economy research. We discuss these below.

\subsubsection{A predominantly Western perspective to the sharing economy}

Despite the significant increase in sharing economy research in recent years, the knowledge produced has been dominated by authors from "Western" institutions, conducting their research in largely Western contexts. While we identified 310 unique institutional affiliations across 48 countries, over one-fourth (26.4\%) of the total output emerged from U.S. based institutions, with institutions in North America and Europe collectively comprising over two-thirds (67.9\%) of the research produced on the sharing economy (please see Figure 5). This situation limits our understanding of the sharing economy, as much of the research on the topic is interpreted through a lens of Western values and understanding. Emerging evidence has shown that the Western-centric perspective might not be applicable to Confucius-dominant societies. For example, Chen (2018) highlighted that Chinese host-guest relationship, Zhu-Ke, is fundamentally culturally different from Western notions of hospitality in that it is based on the conventional hierarchy principle and a host-centric foundation. This observation has implications for the study of host-guest interactions in the rapidly growing sharing economy in China.

Likewise, the contexts in which data were collected also skewed heavily toward Western nations, with over two-thirds (67\%) of the research being conducted in North America or Europe (please see Figure 6). There are very few cross-cultural studies—-less than a fourth of all research (23.05\%) involves more than one country context—and when researchers from various countries 
do collaborate, data are primarily collected in North America and Europe. Moreover, in much of this multi-country research, the data are combined and there is little cross-cultural comparison and/or validation of results. This results in a largely one-sided view of the phenomenon, and limits the generalizability of the results to a global context. These limitations are particularly concerning since many of the factors that contribute to a sharing economy experience, such as trust, interpersonal relationships, and sharing are social constructs that are understood and experienced differently across cultures. In this regard, research such as Boateng et al.'s (2019) study of the determinants of customers' usage of Uber using a social exchange perspective or Buchberger's (2012) study of issues of reciprocity and the social dynamics of hosting Couchsurfers in Morocco are geo-cultural exemplars for research on all sectors of the sharing economy.

\author{
Insert Figure 5 here \\ Insert Figure 6 here
}

\title{
4.3.2 Two disciplinary approaches dominate
}

As previously identified in the results of the co-citation and thematic content analyses, the systematic literature review validated that researchers tend to rely on two predominant disciplinary perspectives to frame and guide their research. As evident in Table 3, fifty-nine percent of all studies were in the related domains of consumer behavior and social psychologywith nearly half of them (46\%) published in 2019 (a growth rate of $165 \%$ over 2018)-while another $24 \%$ of all studies adopted an economics or revenue management perspective, stimulated by Zervas et al.'s (2017) study of Airbnb's impact on Texas hotels. Together, these four 
disciplines proliferated during the third period of research, as previously identified in Figures 2 and 3 , and comprised $83 \%$ of all sharing economy research in hospitality and tourism. Such concentration of disciplinary perspectives limits the nature of the knowledge that emerges, since researchers tend to (re-)use outcome variables common to that discipline (please see Table 4).

For example, in the domain of consumer behavior/social psychology, intention to use/reuse a sharing economy platform comprised $13.6 \%$ of all studies in our review, with other studies focusing on "typical" consumer behavior variables such as satisfaction and loyalty. These outcome variables also point to a "pro-innovation bias" in consumer behavior and social psychology research in the sharing economy, with researchers focusing mainly on positive customer responses and ignoring interesting and meaningful outcomes such as consumer discontinuance (Huang et al., 2020).

The economics/revenue management-oriented studies have largely sought to explain key performance metrics such as price, demand, and revenue/performance for sharing economy platforms, namely Airbnb, and/or traditional incumbents impacted by the sharing economy, namely hotels. Moreover, several studies (e.g., Xie and Mao, 2019) have sought to examine the revenue management practices of different types of accommodation hosts (individual vs. professional), in light of the recognition of the increasing "professionalization" of sharing economy platforms - i.e., the offering of supply by business micro-entrepreneurs (Xie and Chen, 2019), Airbnb in particular (Dogru, Mody, Suess, Line, et al., 2020). Yet, there remains a dearth of knowledge from the perspective of other disciplinary domains, which can only serve to broaden our understanding of the sharing economy. In this regard, Cheng, Zhang, et al.'s (2020) third-period study on Airbnb's boundary-spanning online community represents a timely addition of an organizational-theory perspective to understanding the sharing economy. There is 
also a need for more multi-disciplinary efforts at examining a variety of sharing economy topics to add to the theoretical and empirical repertoire of the knowledge created.

Insert Table 3 here

Insert Table 4 here

\subsubsection{Limited theoretical engagement: theory application and theory development}

Our analysis indicated that researchers' engagement with theory is weak in the sharing economy discourse, as evidenced by two trends. First, despite the fact that the sharing economy is rooted in sociological and psychological shifts in human behavior, only $6.5 \%$ of studies were conceptual, with virtually no emic development of theory. Second, as seen in Table 5, more than half of the studies in our review (51.2\% of total studies) were a-theoretical, failing to identify the use of any particular theory to frame their operationalization. Even when (empirical) studies do incorporate extant theory, most use it to justify a pre-conceived and/or peripheral model, rather than deeply engaging with the tenets of the theory.

Contrary to the other variables of the systematic literature review, which demonstrated a depth of understanding of the sharing economy, but not breadth, researchers identified using 115 different theories to understand the sharing economy, with $86.1 \%$ of these theories having been used only once [for example, Kwok and Xie's (2018) use of similarity attraction theory or Han et al.'s (2019) use of Aristotle's appeals to explain a guest's Airbnb purchase decision]. Nearly a third of studies (32.1\%) using the revenue management perspective leveraged hedonic pricing theory, which is the most common theory adopted in sharing economy research in hospitality and 
tourism. For example, Chen and Xie (2017) developed a hedonic pricing model to test the effects of several utility-based attributes on consumers' valuation of Airbnb listings. Overall, however, our analysis indicated that theoretical application and development is overshadowed by a "number-crunching" mentality that limits deeper understanding of the sharing economy phenomenon, as evidenced in the trend below.

\section{Insert Table 5 here}

\subsubsection{A lack of diversity in research approaches and methods}

As with the disciplinary perspectives identified above, our analysis indicated that the research approaches and methods of data collection and analysis adopted by sharing economy researchers were quite unidimensional. Over $65 \%$ of studies used quantitative methods, $21.8 \%$ were qualitative, and only $6.2 \%$ used mixed methods, a statistic that has not increased proportionally to the overall research output on the sharing economy (please see Table 6). The quantitative studies aligned with consumer behavior and social psychology tended to use survey-based methods, while those using an economics or revenue management perspective largely adopted secondary data collection, which was the most commonly used among all methods $(35.7 \%$ of all studies). In particular, researchers obtained secondary data via webscraping or through readily available sources such as InsideAirbnb.com and AirDNA, enabling the proliferation of the third period of research identified above (2016/2017 onwards). Survey respondents were sourced from a variety of platforms, with MTurk being the most popular.

The lack of mixed methods studies is also indicative of the lack of theory development in sharing economy research, a process that typically entails using multiple methods in multiple 
research contexts to validate findings and develop generalizable knowledge of a phenomenon. Even within the qualitative studies, interviews and secondary data collection were predominant, demonstrating that researchers are not fully leveraging the breadth of insights that different types of qualitative data can provide (e.g., image-based or video data). The notable dearth of qualitative and ethnographic studies also leads to an inability to truly capture the nature of hostguest and guest-guest interactions and relationships, leading to a shallow understanding of the dyadic nature of the sharing economy. In this regard, Bialski's (2012) multi-method study, including autoethnography, of the process by which two strangers become close using Couchsurfing's planned encounters, offers an excellent but unfortunately uncommon example of a deeper epistemological engagement with the sharing economy phenomenon.

Additionally, within the types of research, there was a concentration in the methods of analysis used. As seen in Table 7, quantitative studies relied heavily on regression $(27.3 \%$ of total studies); in particular, to analyze the outcome variables associated with economics/revenue management domain (price, demand, revenue/performance, etc.). SEM-based analyses (14.6\% of total studies) generally analyzed the outcome variables associated with the consumer behavior/social psychology domain (intention to re-use, satisfaction, loyalty, etc.), while qualitative studies primarily used content and thematic analysis (17.9\% of total studies). The use of a wider variety of disciplinary approaches and methods of data collection and analyses would help provide a more holistic view the sharing economy.

Interestingly, we also found that research conducted in North America (by authors in North American institutions) tended to be largely quantitative ( $84.4 \%$ of the time), while research conducted in Europe (33.3\%) and in multiple contexts (i.e., countries/continents (36.2\%) tended to use more qualitative and mixed method approaches. This may be due to the 
availability of better and more readily available secondary data in the North American context, and/or the quantitative bent of the researchers in this part of the world.

\section{Insert Table 6 here}

Insert Table 7 here

\subsubsection{Focusing on the customer at the expense of other stakeholders}

As the body of research on the sharing economy has expanded in the last decade, the majority of work has been conducted from a guest/customer perspective. Over 30\% of studies focused solely on the customer (Table 8). Much work has been done on customer motivations, preferences, behaviors, attitudes, and decision-making when choosing to participate in the sharing economy. However, much less research has focused on other key stakeholders. A little over 14\% of the studies analyzed focused on the sharing platform, and only $6.5 \%$ addressed host needs, attitudes, and behaviors, and other dynamics. The scant research from the host perspective focuses mainly on the economics of hosting, ignoring the interpersonal aspects of the host-guest and hostplatform relationships.

Although more recent research (in and after 2019) has begun to examine the sharing economy from the perspective of other stakeholders — such as residents, incumbent industries, destinations, and academia — we have a limited understanding of the dynamic interplay between the different and multiple stakeholders that comprise the sharing "ecosystem" (Wirtz et al., 2019). In this regard, Dogru, Mody, Suess, McGinley, et al.'s (2020) study on Airbnb's effects on tourism industry employment at the destination level and Chung's (2017) research on how 
online friendships between local residents and tourists are made in a not-for-profit sharing economy platform are noteworthy examples of research that focuses on stakeholders beyond the customer or the platform. Moreover, examining the same issue from the perspective of multiple stakeholders in the same study can offer more nuanced insights into the sharing economy and create knowledge that is inherent to the domain. For example, in addition to examining value cocreation and value co-destruction as perceived by Airbnb customers, Camilleri and Neuhofer's (2017) study could have incorporated host perspectives of social practices that contribute to value formation.

\section{Insert Table 8 here}

\subsubsection{Research on Airbnb overshadows other sectors of the sharing economy}

As seen in Table 9, the vast majority of research on the sharing economy centers focuses on the accommodation sector (90.9\% of total studies), and more specifically on Airbnb (62.7\% of all studies). As previously indicated, while Couchsurfing was the focus of research on the sharing economy in the first period, the exponential growth of Airbnb, accompanied by its extensive coverage in popular media, has resulted in the company becoming the poster-child of the sharing economy (Dann et al., 2019). Additionally, and as indicated above, data on Airbnb has become easy to access and inexpensive, with businesses such as AirDNA providing ready-to-use secondary datasets, contributing to the proliferation of research on the company in the third period; nearly three-fourths (72\%) of output in the research-prolific year of 2019. Unfortunately, the excessive focus on Airbnb leaves significant gaps in the body of knowledge, as other accommodation platforms and sectors of the sharing economy, such as transportation and 
experiences, are largely ignored. Of note, we found only a handful of articles on experience sharing, local guide sharing, and meal sharing. Each of these sectors represents an important and growing segment of the sharing economy and warrants more research to better understand how they impact the hospitality and tourism industry as a whole.

For example, while Uber and Airbnb operate under a similar P2P business model, they present distinct differences in terms of the user experience and how users and drivers/hosts are connected through algorithmic management. In Uber, users are algorithmically assigned to a driver, but in the case of Airbnb, the user plays an active role in selecting their host. Even within the P2P accommodation sector, Chinese P2P platform Xiaozhu and Airbnb are different in terms of their operational practices and features. Importantly, the tourism system now involves many sharing economy players and it is still unknown how these players when integrated co-influence the tourist experience.

Thus, while the dynamics of these other sectors-from the perspective of their various stakeholders such as customers, suppliers/providers/hosts, platforms and others—may be different and unique, our perception of the sharing economy is largely colored by deep knowledge of Airbnb and the accommodation sector. In this regard, research such as that by Mhlanga (2020) on the impact of meal-sharing platforms on incumbent restaurant performance or Furunes and Mkono's (2019) examination of workforce and customer experiences related to P2P foodservice delivery are critical to advancing a more holistic understanding of the sharing economy phenomenon.

Insert Table 9 here 


\section{Discussion and future research}

The purpose of the present study was to critically review the hospitality and tourism literature on the sharing economy. We adopted a comprehensive tri-method approach using bibliometric (cocitation) analysis, thematic content analysis, and a quantitative systematic review to 1) identify the key intellectual foundations of sharing economy research and their evolution over time, and 2) identify opportunities for future research on the sharing economy. The findings from the three methods were coherent and provide a clear picture of the fact that while research on the sharing economy in hospitality and tourism has achieved significant depth, the breadth of our understanding of this area remains somewhat limited. Each of the three periods of research on the sharing economy were marked by a focus on specific thematic areas, with researchers demonstrating limited theoretical engagement and employing a limited range of methods and perspectives (disciplinary, stakeholders, sectors) to examine these themes. These observations point to several opportunities that future researchers can pursue to advance a more nuanced and holistic understanding of the sharing economy. We present these research opportunities, in addition to those alluded to above, in Table 10. Consistent with Prayag and Ozanne (2018), we structure the thematic research opportunities using a multi-level perspective (MLP).

The macro-level domain of the MLP includes research that examines the sharing economy at the level of societies, cultures, countries, regions, and political and economic systems. Our analysis indicated that the macro impacts of sharing economy were less discussed and empirically examined in extant research, mainly due to challenges with the availability of data and/or the complexity of macro-level issues (e.g., platform governance, or regulation). This observation was especially evidenced in the disciplinary foci of extant research — consumer behavior and social psychology and economics and revenue management - and on the focus on 
outcomes variables of relevance mainly to the meso and micro-level domains of the sharing economy. On the other hand, research outside of the field of hospitality and tourism has begun to examine macro-level issues such as the factors that influence the entry of sharing economy providers, including industry growth, and how the availability of underutilized resources increases entry onto the platforms while the strictness of regulation reduces the likelihood of entry (Gerwe et al., 2020).

While this emerging evidence provides much needed insights, a fuller picture of the macro level of the sharing economy still remains unclear. Questions have been raised in the literature in relation to the economic, social, political, technological, and ecological sustainability of the sharing economy, particularly with the dramatic impacts of the COVID-19 pandemic. COVID-19 has inevitably challenged the sustainability of sharing economy business models. For example, Chen et al. (2020) found that Airbnb hosts in greater Sydney suffered a revenue loss that was 6.5 times more than the Airbnb platform itself. With hosts not being eligible for financial aid offered by the government, unlike traditional businesses like hotels, the COVID-19 pandemic demonstrates the vulnerability of the sharing economy during a time of crisis, widening public debate on the sharing economy's contribution to sustainable tourism.

At the same time, some of the issues raised by the extant literature about sharing economy models might no longer be perceived as important issues by various stakeholders. For example, local residents' lobbying against Airbnb-like platforms on the basis of their impacts on the long term rental market (Mody et al., 2020) might no longer be valid as evidence shows that more professional Airbnb hosts are considering shifting to long-term rental for Airbnb (Dolnicar and Zare, 2020) following COVID-19. It will be timely to examine whether such issues will still be prevalent or whether new issues will arise in the rapidly evolving macro-environment. 
In addition to these macro-level questions about how sustainability is conceptualized and measured in the sharing economy and the organizational resilience of sharing economy businesses, issues of platform governance and regulation in response to the sharing economy's various impacts - including environmental sustainability, algorithmic management, and platforms' entry into stock market—warrant examination. For example, by understanding how algorithmic management works in the sharing economy, platforms can provide evidence to regulatory authorities in formulating relevant strategies, and, to some extent, regulation to reduce adverse outcomes on society, including potential digital discrimination (Cheng and Foley, 2018).

Moreover, the macro-level of the sharing economy can particularly benefit from researchers adopting a wider range of disciplinary perspectives and from multi-disciplinary efforts. For example, the ecological impacts of the sharing economy are particularly complex (Frenken and Schor, 2017), and require further research to challenge previous notions of the assumed environmental sustainability of the sharing economy. In this regard, Cheng, Chen, et al.'s (2020) study that combines a framework and methodology from tourism, environmental engineering, and geography reminds us that going beyond calculating the direct carbon footprint of Airbnb to including the company's induced carbon footprint paints a different picture of the its environmental impacts. As such, evidence from these macro-level areas of future research will enable stakeholders to formulate informed strategies for the long-term sustainability of the sharing economy.

The meso-level domain includes issues that impact organizations, such as local communities, businesses, industry associations, and traditional incumbent providers, such as hotels. The meso-level analysis of the sharing economy literature indicated that more research is needed on the impacts of and on sharing economy entities, such as traditional hotels and sharing 
platform companies. Extant research included in this review regarding these issues focused mainly on supply and demand, such as examining the impact of Airbnb supply on hotel industry demand using economics and revenue management perspectives. While these will continue to be important and warrant further research, impending developments highlight the need for a deeper examination of important meso-level questions.

For example, the onset of COVID-19 has resulted in low hotel occupancy and low room rates, particularly in vacation destinations, due to travel restrictions imposed by local and regional governments. This will undoubtedly change the nature of the delicate equation between the supply of homesharing properties and traditional hotel offerings, as price and availability fluctuate in the different stage of the pandemic. This may affect other micro and macro-level issues, such as marketing and regulation. Indeed, many cities have already taken advantage of the vacancies of homesharing properties to reclaim them for long-term rental housing for locals (Bevins, 2020). Likewise, the body of knowledge about consumer psychology when choosing between traditional hotels and homesharing options will need to be updated in an environment where such important decision-making elements as price and availability are rendered less important, and issues such as hygiene and safety become paramount. Technological advancements will also impact meso-level considerations for sharing economy research. For example, the advent of autonomous cars will undoubtedly impact the consideration set of a consumer deliberating transportation, with untold effects on the ridesharing industry.

The impact of the sharing economy on destinations and host communities emerged in our analysis as a vastly under-researched area in the hospitality and tourism literature. While some articles did address these issues, there is still a great deal to be known about how a sudden influx of tourism, made possible by the availability of addition lodging in the form of homesharing, 
impacts not only the economic situation of a community but also the social and cultural dimensions of host cities. Moreover, with the COVID-19 pandemic, will destinations and locals demonstrate greater pushback towards visitors in their communities? Will they demonstrate support for stricter regulations and requirements, such as proof of vaccination prior to issuing visas or allowing entry to travelers?

For example, local pushback towards Airbnb listings in Lake Tahoe led the company to ask visitors to sign an attestation form that their stay is permitted within local guidelines before booking (Thomas, 2021). In particular, the sharing economy's contribution to overtourism, an issue that has received considerable media coverage but not academic attention (e.g., Tait, 2020), should form an important component of future meso-level research that impacts platforms, incumbents, communities, and the tourism industry at the destination as a whole. Specifically, an understanding of strategies that can mitigate the sharing economy's contribution to overtourism holds immense academic and practical value.

The micro-level domain addresses the impact of the sharing economy on individuals and relationships, including consumers and suppliers. While research on the customer experience has proliferated in recent years, as evidenced in high percentage of studies focusing on the customer (nearly one-third of the total) and the disciplinary foci of consumer behavior and social psychology, there remains an opportunity to expand the inquiry in two key ways. First, our results indicated that the overwhelming majority of sharing economy research has been conducted on P2P accommodation, at the expense of other sharing economy sectors, such as transportation, meal sharing, and experience sharing. In order to obtain a more holistic understanding of the sharing economy, it is imperative that research on the nature of the customer experience be initiated in these supplementary and growing meso-level domains of the 
sharing economy. For example, in a recent study (outside the scope of the present review), Lin et al. (2021) identified several motivational differences between participation in P2P dining, as a novel product in local and overseas food tourism, and conventional dining. Second, there remains a need for research that examines the changing nature of the customer experience, as enabled by trends in the respective meso-sectors of the sharing economy. For example, accelerated by the restrictions on movement due to the COVID-19 pandemic, Airbnb and Amazon both launched online tours and experiences platforms that add a P2P component to "virtual tourism" (Porter, 2020): how do these virtual experiences affect how travelers experience a destination and its culture?

From a supplier perspective, while much research has examined $\mathrm{P} 2 \mathrm{P}$ accommodation hosts' attributes and how these impact listing performance using secondary, indicative data, primary research that examines different dimensions of suppliers' actual behavior is limited. For example, in the case of $\mathrm{P} 2 \mathrm{P}$ accommodation, do hosts actively or passively manage pricing decisions? To what extent are suppliers across the various sharing economy sectors serviceoriented? How do they review customers? Does participating in the sharing economy enhance supplier well-being? Additionally, very little work has been done on individuals who simultaneously act as consumer and host ("prosumers"), despite the fact that this is a common occurrence in the sharing economy. These issues, among others, bear future consideration at the micro-level of the sharing economy.

In addition to the thematic research opportunities, our findings point to several methodological considerations for future research (Table 10). In general, extant research on the sharing economy has been largely conducted in Western contexts, using either survey data (from MTurk) or secondary data. There is a significant lack of diversity in contexts, data collection 
methods, sample populations, outcome variables, and analysis methods. Hospitality and tourism researchers should use these gaps as inspiration for conducting studies using a variety of contexts, research designs, and analysis methods, in order to deepen our understanding of the phenomenon. While some of these gaps are not unique to the sharing economy, but applicable to hospitality and tourism research more generally, they bear mention since they have important consequences for the nature and scope of knowledge that is created about the sharing economy.

\section{Insert Table 10 here}

Most importantly, the results of this study highlighted the fact that extant research has primarily been concerned with the "what" of the sharing economy, while largely ignoring the questions of "why" and "how." The use of survey data and secondary data is useful for describing the phenomenon (the "what"), but stops short of providing a full picture of the mechanisms through which the sharing economy works (the "how"). Our suggestions for future research to address the how questions are significantly covered in Table 10. Moreover, because the majority of past studies either have no theoretical basis or seem to merely use existing theories as a post-hoc justification for data mining exercises, little is understood about the subjective experiences, psychological factors, and emotional mechanisms that underlie the why of the sharing economy; thus theory development and expansion has been lacking in the sharing economy literature.

Future research could focus on creating and enhancing theory in the sharing economy domain. In particular, researchers could develop more conceptual and positioning papers to propose ideas that challenge our understanding of the sharing economy and encourage future 
scholars to go beyond the current thematic and methodological limitations of literature on the topic. The use of disciplinary approaches beyond the four predominant ones identified in the present study will further enhance both theory application and theory development. Moreover, the use of inductive methodological approaches, beyond the current focus on quantitative data collection and analysis, can enable researchers to explore the why behind the sharing economy from a consumer, provider, and other stakeholder perspective.

In comparison with previous literature reviews on the sharing economy, the salience of this critical review lies in its comprehensiveness of scope, methodology, and timespan. A significant limitation is that the timeline under investigation predates the onset of COVID-19, which has proven to be a major disruptor to the hospitality and tourism industry. However, the articles chosen for this critical review covered a timespan that ended in May 2020; while COVID-19 had already significantly impacted the hospitality and tourism industry by then, all of the studies reviewed had collected data and been accepted/published prior to the onset of the pandemic. Thus, the present review represents the largest and most comprehensive assessment of the state of research on the sharing economy in hospitality and tourism journals prior to COVID-19, and, as such, can serve as a valuable baseline for future reviews of sharing economy research during and after the pandemic. 


\section{References}

Alrawadieh, Z., Alrawadieh, Z. and Cetin, G. (2020), "Digital transformation and revenue management: Evidence from the hotel industry", Tourism Economics, SAGE Publications Ltd, available at:https://doi.org/10.1177/1354816620901928.

Altinay, L. and Taheri, B. (2019), "Emerging themes and theories in the sharing economy: a critical note for hospitality and tourism", International Journal of Contemporary Hospitality Management, Vol. 31 No. 1, pp. 180-193.

Belarmino, A. and Koh, Y. (2020), “A critical review of research regarding peer-to-peer accommodations", International Journal of Hospitality Management, Elsevier, Vol. 84, available at:https://doi.org/10.1016/j.ijhm.2019.05.011.

Bevins, V. (2020), "The European Cities Using the Pandemic As a Cure for Airbnb", New York Magazine, available at: https://nymag.com/intelligencer/2020/08/in-europe-covid-19-is-anopportunity-to-regulate-airbnb.html.

Bialski, P. (2012), "Technologies of hospitality: How planned encounters develop between strangers", Hospitality \& Society, Vol. 1 No. 3, pp. 245-260.

Boateng, H., Kosiba, J.P.. and Okoe, A.F. (2019), "Determinants of consumers' participation in the sharing economy: A social exchange perspective within an emerging economy context", International Journal of Contemporary Hospitality Management, Emerald Publishing Limited, Vol. 31 No. 2, pp. 718-733.

Buchberger, J. (2012), "Hospitality, secrecy and gossip in Morocco: Hosting CouchSurfers against great odds", Hospitality \& Society, Vol. 1 No. 3, pp. 299-315.

Camilleri, J. and Neuhofer, B. (2017), "Value co-creation and co-destruction in the Airbnb sharing economy", International Journal of Contemporary Hospitality Management, Vol. 29 No. 9, pp. 2322-2340.

Chen, C. (2014), The Citespace Manual, Drexel University, Philadelphia.

Chen, G., Cheng, M., Edwards, D. and Xu, L. (2020), "COVID-19 pandemic exposes the vulnerability of the sharing economy: a novel accounting framework", Journal of Sustainable Tourism, Routledge, pp. 1-18.

Chen, X. (2018), "Multidimensional study of hospitality and the host-guest paradigm in China", International Journal of Contemporary Hospitality Management, Emerald Publishing Limited, Vol. 30 No. 1, pp. 495-513.

Chen, Y. and Xie, K. (2017), "Consumer valuation of Airbnb listings: a hedonic pricing approach”, International Journal of Contemporary Hospitality Management, Emerald, Vol. 29 No. 9, pp. 2405-2424.

Cheng, M. (2016a), "Current sharing economy media discourse in tourism", Annals of Tourism Research, Elsevier Ltd, Vol. 60, pp. 111-114.

Cheng, M. (2016b), "Sharing economy: A review and agenda for future research", International Journal of Hospitality Management, Elsevier Ltd, Vol. 57, pp. 60-70.

Cheng, M., Chen, G., Wiedmann, T., Hadjikakou, M., Xu, L. and Wang, Y. (2020), "The sharing economy and sustainability - assessing Airbnb's direct, indirect and induced carbon footprint in Sydney", Journal of Sustainable Tourism, Routledge, Vol. 28 No. 8, pp. 10831099.

Cheng, M., Edwards, D., Darcy, S. and Redfern, K. (2018), “A Tri-Method Approach To A Review of Adventure Tourism Literature : Bibliometric Analysis, Content Analysis, and A Quantitative Systematic Literature Review", Journal of Hospitality and Tourism Research, 
Vol. 42 No. 6, pp. 997-1020.

Cheng, M. and Foley, C. (2018), "The sharing economy and digital discrimination: The case of Airbnb", International Journal of Hospitality Management, Vol. 70, pp. 95-98.

Cheng, M. and Jin, X. (2019), "What do Airbnb users care about? An analysis of online review comments", International Journal of Hospitality Management, Elsevier, Vol. 76, pp. 58-70.

Cheng, M., Zhang, G. and Wong, A.I. (2020), "Spanning across the boundary of Airbnb host community: a network perspective", International Journal of Hospitality Management, Elsevier Ltd, Vol. 89, p. 102541.

Chung, J. (2017), "Online friendships in a hospitality exchange network: a sharing economy perspective", International Journal of Contemporary Hospitality Management, Vol. 29 No. 11, pp. 2962-2976.

Dann, D., Teubner, T. and Weinhardt, C. (2019), "Poster child and guinea pig - insights from a structured literature review on Airbnb", International Journal of Contemporary Hospitality Management, Vol. 31 No. 1, pp. 427-473.

Dogru, T., Mody, M., Suess, C., Line, N. and Bonn, M. (2020), “Airbnb 2.0: Is it a sharing economy platform or a lodging corporation?”, Tourism Management, Vol. 78, p. 104049.

Dogru, T., Mody, M., Suess, C., McGinley, S. and Line, N.D. (2020), "The Airbnb paradox: Positive employment effects in the hospitality industry", Tourism Management, Vol. 77, available at:https://doi.org/https://doi.org/10.1016/j.tourman.2019.104001.

Dolnicar, S. (2019), "A review of research into paid online peer-to-peer accommodation: Launching the Annals of Tourism Research curated collection on peer-to-peer accommodation", Annals of Tourism Research, Elsevier, Vol. 75 No. September 2018, pp. $248-264$.

Dolnicar, S. and Zare, S. (2020), "COVID19 and Airbnb-Disrupting the disruptor", Annals of Tourism Research, available at:https://doi.org/https://doi.org/10.1016/j.annals.2020.102961.

Frenken, K. and Schor, J. (2017), "Putting the sharing economy into perspective", Environmental Innovation and Societal Transitions, Vol. 23, pp. 3-10.

Furunes, T. and Mkono, M. (2019), "Service-delivery success and failure under the sharing economy", International Journal of Contemporary Hospitality Management, Emerald Publishing Limited, Vol. 31 No. 8, pp. 3352-3370.

Germann Molz, J. (2012), "CouchSurfing and network hospitality: 'It's not just about the furniture", Hospitality \& Society, Vol. 1 No. 3, pp. 215-225.

Gerwe, O., Silva, R. and Castro, J. de. (2020), "Entry of Providers Onto a Sharing Economy Platform: Macro-Level Factors and Social Interaction", Entrepreneurship Theory and Practice, SAGE Publications Inc, available at:https://doi.org/10.1177/1042258720903404.

Gutierrez, J., García-Palomares, J.C., Romanillos, G. and Salas-olmedo, M.H. (2017), “The eruption of Airbnb in tourist cities : Comparing spatial patterns of hotels and peer-to-peer accommodation in Barcelona", Tourism Management, Vol. 62, pp. 278-291.

Guttentag, D. (2015), "Airbnb: disruptive innovation and the rise of an informal tourism accommodation sector", Current Issues in Tourism, Vol. 18 No. 12, pp. 1192-1217.

Guttentag, D. (2019), "Progress on Airbnb : a literature review", Journal of Hospitality and Tourism TechnologyTourism Technology, Vol. 10 No. 4, pp. 814-844.

Guttentag, D., Smith, S., Potwarka, L. and Havitz, M. (2018), "Why Tourists Choose Airbnb: A Motivation-Based Segmentation Study", Journal of Travel Research, Vol. 57 No. 3, pp. 342-359.

Han, H., Shin, S., Chung, N. and Koo, C. (2019), "Which appeals (ethos, pathos, logos) are the 
most important for Airbnb users to booking?", International Journal of Contemporary Hospitality Management, Emerald Publishing Limited, Vol. 31 No. 3, pp. 1205-1223.

Heo, C.Y. (2016), "Sharing economy and prospects in tourism research", Annals of Tourism Research, Elsevier Ltd, Vol. 58, pp. 166-170.

Hossain, M. (2020), "International Journal of Hospitality Management Sharing economy : A comprehensive literature review", International Journal of Hospitality Management, Vol. 87, available at:https://doi.org/10.1016/j.ijhm.2020.102470.

Huang, D., Coghlan, A. and Jin, X. (2020), "Understanding the drivers of Airbnb discontinuance", Annals of Tourism Research, Elsevier, Vol. 80, available at:https://doi.org/10.1016/j.annals.2019.102798.

Kim, C., Bai, B., Kim, P. and Chon, K. (2018), "Review of reviews : A systematic analysis of review papers in the hospitality and tourism literature", International Journal of Hospitality Management, Elsevier, Vol. 70, pp. 49-58.

Kuhzady, S., Seyfi, S. and Béal, L. (2020), "Peer-to-peer ( P2P ) accommodation in the sharing economy:a review", Current Issues in Tourism, Taylor \& Francis, pp. 1-16.

Kwok, L. and Xie, K. (2018), "Buyer-seller similarity: Does it lead to a successful peer-to-peer transaction of room-sharing services?", International Journal of Contemporary Hospitality Management, Emerald Publishing Limited, Vol. 30 No. 9, pp. 2925-2944.

Lin, P., Ok, C.. and Au, W.. (2021), "Peer-to-Peer Dining: A Motivation Study", Journal of Hospitality \& Tourism Research, pp. 1-26.

Mhlanga, O. (2020), “'Meal-sharing' platforms: a boon or bane for restaurants?", Current Issues in Tourism, Routledge, pp. 1-18.

Mody, M. and Hanks, L. (2019), "Consumption Authenticity in the Accommodations Industry: The Keys to Brand Love and Brand Loyalty for Hotels and Airbnb", Journal of Travel Research, SAGE Publications Inc, Vol. 59 No. 1, pp. 173-189.

Mody, M., Woosnam, K.M., Suess, C. and Dogru, T. (2020), "Hapless victims or empowered citizens? Understanding residents' attitudes towards Airbnb using Weber's Theory of Rationality and Foucauldian concepts", Journal of Sustainable Tourism, Routledge, pp. 123.

Pickering, C. and Byrne, J. (2014), "The benefits of publishing systematic quantitative literature reviews for $\mathrm{PhD}$ candidates and other early-career researchers", Higher Education Research \& Development, Routledge, Vol. 33 No. 3, pp. 534-548.

Porter, J. (2020), “Amazon starts offering virtual classes and sightseeing tours via new Explore platform", The Verge.

Prayag, G. and Ozanne, L.K. (2018), “A systematic review of peer-to-peer (P2P) accommodation sharing research from 2010 to 2016: progress and prospects from the multi-level perspective", Journal of Hospitality Marketing and Management, Routledge, Vol. 27 No. 6, pp. 649-678.

Ranjbari, M., Shams Esfandabadi, Z. and Scagnelli, S.. (2020), "A big data approach to map the service quality of short-stay accommodation sharing", International Journal of Contemporary Hospitality Management, Emerald Publishing Limited, Vol. 32 No. 8, pp. 2575-2592.

Sainaghi, R. (2020), "The current state of academic research into peer-to-peer accommodation platforms", International Journal of Hospitality Management, Elsevier, Vol. 89, available at:https://doi.org/10.1016/j.ijhm.2020.102555.

Sainaghi, R. and Baggio, R. (2020), "Clusters of topics and research designs in peer-to-peer 
accommodation platforms", International Journal of Hospitality Management, Elsevier, Vol. 88, available at:https://doi.org/10.1016/j.ijhm.2019.102393.

Sainaghi, R., Köseoglu, M. and Mehraliyev, F. (2020), "The intellectual structure of the sharing economy", Tourism Economics, available at:https://doi.org/10.1177/1354816620920434.

Sainaghi, R., Köseoglu, M.A., Angella, F. and Mehraliyev, F. (2020), "Sharing economy : a cocitation analysis", Current Issues in Tourism, Taylor \& Francis, Vol. 23 No. 8, pp. 929-937.

Tait, R. (2020), "Prague Aims to Restrict Airbnb to Curb Overtourism", Skift.

Thomas, G. (2021), "Airbnb is asking guests for a new requirement before booking stays in California during pandemic", San Francisco Chronicle, available at:

https://www.sfchronicle.com/travel/article/Airbnb-rolls-out-new-requirement-forCalifornia-15848487.php.

Tussyadiah, I.P. and Pesonen, J. (2015), "Impacts of Peer-to-Peer Accommodation Use on Travel Patterns", Journal of Travel Research, SAGE Publications Inc, Vol. 55 No. 8, pp. 1022-1040.

Wirtz, J., So, K., Mody, M., Liu, S. and Chun, H. (2019), "Platforms in the Peer-to-Peer Sharing Economy", Journal of Service Management, Vol. 30 No. 4, pp. 452-483.

Wu, J., Ma, P. and Xie, K. (2017), "In sharing economy we trust: the effects of host attributes on short-term rental purchases", International Journal of Contemporary Hospitality Management, Emerald Publishing Limited, Vol. 29 No. 11, pp. 2962-2976.

Xie, K. and Chen, Y. (2019), "Effects of host incentives on multiple listings in accommodation sharing", International Journal of Contemporary Hospitality Management, Emerald Publishing Limited, Vol. 31 No. 4, pp. 1995-2013.

Xie, K. and Mao, Z. (Eddie). (2019), "Locational Strategy of Professional Hosts: Effect on Perceived Quality and Revenue Performance of Airbnb Listings", Journal of Hospitality and Tourism Research, Vol. 43 No. 86685, pp. 919-929.

Zervas, G., Proserpio, D. and Byers, J.W. (2017), "The Rise of the Sharing Economy: Estimating the Impact of Airbnb on the Hotel Industry", Journal of Marketing Research, Vol. 54 No. 5, pp. 687-705.

Zhu, L., Lin, Y. and Cheng, M. (2020), "Sentiment and guest satisfaction with peer-to-peer accommodation: When are online ratings more trustworthy?", International Journal of Hospitality Management, Elsevier, Vol. 86, available at:https://doi.org/10.1016/j.ijhm.2019.102369.

Zhu, Y., Cheng, M., Wang, J., Ma, L. and Jiang, R. (2019), "The construction of home feeling by Airbnb guests in the sharing economy: A semantics perspective", Annals of Tourism Research, Vol. 75, pp. 308-321. 
${ }^{3}$ Table 1. Previous review studies on the sharing economy: key findings and limitations 4

\begin{tabular}{|c|c|c|c|}
\hline $\begin{array}{ll}\sqrt[5]{6} & \text { Author and } \\
6 & \text { Year }\end{array}$ & Title & Key findings & Limitations \\
\hline 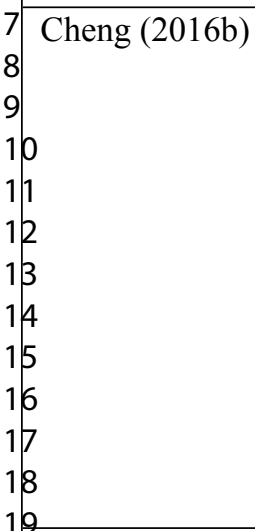 & $\begin{array}{l}\text { Sharing economy: A review } \\
\text { and agenda for future } \\
\text { research }\end{array}$ & $\begin{array}{l}\text { Identified three broad areas of foci with sharing } \\
\text { economy research in general: (1) Sharing } \\
\text { economy's business models and its impacts, (2) } \\
\text { nature of the sharing economy, and (3) Sharing } \\
\text { economy's sustainability development as well as } \\
\text { two areas of foci in tourism and hospitality } \\
\text { specifically: (1) Sharing economy's impacts on } \\
\text { destinations and tourism services (2) Sharing } \\
\text { economy's impacts on tourists } \\
\text { The sharing economy has a strong intellectual } \\
\text { tradition from lifestyle and social movement } \\
\text { field, consumption practice and sharing } \\
\text { paradigm }\end{array}$ & $\begin{array}{l}\text { - Scope: Largely focused on research in non-hospitality and tourism } \\
\text { journals } \\
\text { - } \\
\text { - Tethodology: Used co-citation analysis and content analysis } \\
\text { recent proliferation of research (2016-2020), which has been } \\
\text { substantial }\end{array}$ \\
\hline $\begin{array}{l}2 p^{2} \mathrm{Heo}(2016) \\
21 \\
22 \\
23\end{array}$ & $\begin{array}{l}\text { Sharing economy and } \\
\text { prospects in tourism } \\
\text { Research }\end{array}$ & $\begin{array}{l}\text { Identifies the topics covered by early research } \\
\text { on the sharing economy, such as its impact on } \\
\text { the traditional hospitality sector, and offers } \\
\text { suggestions for future research (much of which } \\
\text { has been conducted since) }\end{array}$ & $\begin{array}{l}\text { Methodology and output: Not an empirical, rather a discussion-based } \\
\text { review based on selective discourse on the sharing economy } \\
\text { Timespan: published in 2016; does not include the recent proliferation } \\
\text { of research (2017-2020), which has been substantial and important to } \\
\text { defining the study of the sharing economy }\end{array}$ \\
\hline $\begin{array}{l}24 \\
25 \text { Prayag and } \\
26 \\
27 \\
28 \\
29 \\
30\end{array}$ & $\begin{array}{l}\text { A systematic review of peer- } \\
\text { to-peer }(P 2 P) \\
\text { accommodation sharing } \\
\text { research from } 2010 \text { to } \\
\text { 2016: progress and } \\
\text { prospects from the multi- } \\
\text { level perspective }\end{array}$ & $\begin{array}{l}\text { - } \begin{array}{l}\text { Adopted a multi-level perspective (MLP) to } \\
\text { conceptualize the literature on the sharing } \\
\text { economy } \\
\text { - } \\
\text { Identified seven key themes: conceptual } \\
\text { development; regulation; macrolevel impacts; } \\
\text { regime response; host behavior; guest/host } \\
\text { experience; and marketing issues }\end{array} \\
\end{array}$ & $\begin{array}{l}\text { - Scope: Only reviewed P2P accommodation } \\
\text { - Timespan: } 71 \text { articles between } 2010 \text { and 2016; does not include the } \\
\text { recent proliferation of research (2017-2020), which has been } \\
\text { substantial }\end{array}$ \\
\hline $\begin{array}{l}31 \text { Guttentag } \\
32(2019) \\
33 \\
34 \\
35 \\
36 \\
37 \\
38 \\
39 \\
40 \\
41\end{array}$ & $\begin{array}{l}\text { Progress on Airbnb: } \\
\text { a literature review }\end{array}$ & $\begin{array}{l}\text { The majority of Airbnb research has been } \\
\text { published quite recently, often in } \\
\text { hospitality/tourism journals, and the research has } \\
\text { been conducted primarily by researchers in the } \\
\text { USA/Canada and Europe } \\
\text { - Papers on the sharing economy divided into six } \\
\text { thematic categories: Airbnb guests, Airbnb } \\
\text { hosts, Airbnb supply and its impacts on } \\
\text { destinations, Airbnb regulation, Airbnb's } \\
\text { impacts on the tourism sector and the Airbnb } \\
\text { company }\end{array}$ & $\begin{array}{l}\text { - Scope: Only reviewed Airbnb, not P2P accommodation as a whole or } \\
\text { other sectors of the sharing economy } \\
\text { - Methodology: Used thematic content analysis only } \\
\text { - Timespan: Articles up to October 2018; does not include the recent } \\
\text { proliferation of research (2019-2020), which has been substantial }\end{array}$ \\
\hline
\end{tabular}




\begin{tabular}{|c|c|c|c|}
\hline $\begin{array}{l}3 \\
4 \\
5 \\
6\end{array}$ & & $\begin{array}{l}\text { - Consistent findings have begun to emerge on } \\
\text { several important topics, including guests' } \\
\text { motivations and the geographical dispersion of } \\
\text { listings }\end{array}$ & \\
\hline \begin{tabular}{l|l}
7 & Ozdemir and \\
8 & Turker (2019) \\
9 & \\
10 \\
1 \\
12 \\
12 \\
13 \\
14 \\
15 \\
16 \\
17 \\
18 \\
10
\end{tabular} & $\begin{array}{l}\text { Institutionalization of the } \\
\text { sharing in the context of } \\
\text { Airbnb: a systematic } \\
\text { literature review and content } \\
\text { analysis }\end{array}$ & $\begin{array}{l}\text { Academic literature and public media articles } \\
\text { covered parallel themes pertaining to the sharing } \\
\text { economy, including legal issues, social issues, } \\
\text { economic issues, Airbnb's public relations and } \\
\text { publicity, benefits, Airbnb's impact on } \\
\text { destinations, hotel competition, nature of the } \\
\text { sharing economy } \\
\text { Themes including technology, customer } \\
\text { behavior and sustainability were unique to } \\
\text { academic literature, while CSR, safety and } \\
\text { security, growth, politics, and insurance were } \\
\text { unique to media articles on the sharing economy }\end{array}$ & $\begin{array}{l}\text { - Scope: Media articles analyzed pertaining to Airbnb only and not other } \\
\text { sectors of the sharing economy } \\
\text { Methodology and output: Used quantitative systematic literature } \\
\text { review only. Limited sample of } 56 \text { journal articles on the sharing } \\
\text { economy. Does not identify research gaps and opportunities for future } \\
\text { research } \\
\text { Timespan: Articles up to December } 2017 \text {; does not include the recent } \\
\text { proliferation of research (2018-2020), which has been substantial }\end{array}$ \\
\hline $\begin{array}{ll}20 & \text { Dolnicar } \\
2 & (2019) \\
22 & 23 \\
23 & 24 \\
25 & \end{array}$ & $\begin{array}{l}\text { A review of research into } \\
\text { paid online peer-to-peer } \\
\text { accommodation: } \\
\text { Launching the Annals of } \\
\text { Tourism Research Curated } \\
\text { Collection on } \\
\text { peer-to-peer accommodation }\end{array}$ & $\begin{array}{l}\text { - Offers a knowledge map along the two } \\
\text { dimensions of topics investigated (P2P networks } \\
\text { and "the environment", "public policy", } \\
\text { "society", "tourism industry"), and form of } \\
\text { knowledge generated (concepts, associations, } \\
\text { and causes-and-effects) }\end{array}$ & $\begin{array}{l}\text { - Scope: Only reviewed P2P accommodation } \\
\text { - Methodology and output: Lack of a documented, systematic method of } \\
\text { analysis, which precludes duplication } \\
\text { Timespan: Articles up to October 2018; does not include the recent } \\
\text { proliferation of research (2019-2020), which has been substantial }\end{array}$ \\
\hline $\begin{array}{l}26 \\
27 \text { Altinay and } \\
28 \\
28 \\
30 \\
30 \\
31 \\
32 \\
33 \\
34 \\
35 \\
36\end{array}$ & $\begin{array}{l}\text { Emerging themes and } \\
\text { theories in } \\
\text { the sharing economy: a } \\
\text { critical } \\
\text { note for hospitality and } \\
\text { tourism }\end{array}$ & $\begin{array}{l}\text { Identifies the application of nine major } \\
\text { theories - theory of planned behavior, } \\
\text { complexity theory, social exchange theory, } \\
\text { NAM, value co-creation, transaction cost theory, } \\
\text { social comparison theory, SCT, and S-O-R- } \\
\text { and seven key themes-trust and reputation, } \\
\text { disruptive customer behaviors, consumer choice } \\
\text { and segmentation, pricing strategies, socially } \\
\text { excluded customers, traveler personality, and } \\
\text { customer satisfaction-to sharing economy } \\
\text { research in hospitality and tourism }\end{array}$ & $\begin{array}{l}\text { - Methodology and output: Lack of a documented, systematic method of } \\
\text { analysis, which precludes duplication. Less emphasis on research gaps } \\
\text { and opportunities, but more on what has already been done. Gaps } \\
\text { identified appear disconnected from findings }\end{array}$ \\
\hline $\begin{array}{l}37 \text { Dann, } \\
38 \text { Teubner, and } \\
39 \text { Weinhardt } \\
40(2019) \\
41\end{array}$ & $\begin{array}{l}\text { Poster child and guinea pig } \\
\text { - insights from a structured } \\
\text { literature review on } \\
\text { Airbnb }\end{array}$ & $\begin{array}{l}\text { Research on Airbnb is highly diverse in terms of } \\
\text { domains, methods and scope; motives for using } \\
\text { Airbnb are manifold (e.g. financial, social and } \\
\text { environmental); trust and reputation are } \\
\text { considered crucial; the platform's variety is }\end{array}$ & $\begin{array}{l}\text { - Scope: Only reviewed Airbnb, not P2P accommodation as a whole or } \\
\text { other sectors of the sharing economy } \\
\text { Methodology and output: Classification of studies into a-priori themes } \\
\text { via quantitative systematic review, in contrast with topics emerging } \\
\text { from the data }\end{array}$ \\
\hline
\end{tabular}


\begin{tabular}{l|l|l}
\hline 3 \\
4
\end{tabular}$\quad \begin{aligned} & \text { reflected in prices; and the majority of work is } \\
& \text { based on surveys and empirical data while }\end{aligned}$ 4
5
6
7
8
9
10
1

\section{Belarmino and} $13 \operatorname{Koh}(2020)$

14

15

16

17

18$$
\begin{aligned}
& 19 \\
& 20 \\
& 21 \\
& 22 \\
& 23 \\
& 24 \\
& 25 \\
& 26 \\
& 27 \\
& 28
\end{aligned}
$$$$
\begin{aligned}
& 20 \\
& 21 \\
& 22 \\
& 23 \\
& 24 \\
& 25 \\
& 26 \\
& 27 \\
& 28
\end{aligned}
$$$$
\text { Seyfi, and }
$$$$
\text { Béal (2020) }
$$
experiments are scarce

- The set of under-represented areas includes cross-cultural investigations, field experiments and audit studies, the consideration of dynamic processes (e.g. based on panel data), Airbnb's "experiences" and automated pricing algorithms and the rating distribution's skewness \begin{tabular}{l|l}
$\begin{array}{l}\text { A critical review of research } \\
\text { regarding peer-to-peer }\end{array}$ & - $\begin{array}{l}\text { Topics explored in the sharing economy } \\
\text { literature on P2P accommodation include: }\end{array}$
\end{tabular} accommodations consumer behavior, legal issues, conceptualizing $\mathrm{P} 2 \mathrm{P}$ accommodations, in the sharing economy, revenue management, trust and mistrust, $\mathrm{P} 2 \mathrm{P}$ accommodations and hotels, owner motivations, affordable housing concerns, and emerging fields

Peer-to-peer $(\mathrm{P} 2 \mathrm{P}) \quad$ - Airbnb is a major focus for tourism scholars

accommodation in the

- The provision of authentic experiences, environmental concerns, and socialization are important themes in $\mathrm{P} 2 \mathrm{P}$ accommodation research, with trust and negative attitudes of established businesses and government regarded as the main barriers of P2P development

- Study examines the evolution of sharing economy literature between 2000 and 2015 and 2016-2019

- Topics explored in the sharing economy

Te current state of academic research into peer-to-peer accommodation platforms

Clusters of topics and research designs in peer-topeer accommodation Platforms

literature on $\mathrm{P} 2 \mathrm{P}$ accommodation include: $\mathrm{P} 2 \mathrm{P}$ platforms (business model), demand-side studies, hosts (performance, pricing, and location patterns), guest-host relationships, economic impact studies, social impact, regulation, and literature review studies on the sharing economy

- Study uses a unique cross-citation approach

- P2P accommodation research can be grouped in nine clusters structured around six blocks: conceptual studies, hotel industry, local
- Scope: Only reviewed P2P accommodation

- Methodology: Descriptive analysis and text mining for commonly used words

- Timespan: Articles between 2010 and 2017; does not include the recent proliferation of research, which has been substantial

- Scope: Only reviewed P2P accommodation

- Methodology and output: Used quantitative systematic review only. Less emphasis on research gaps and future opportunities, more on what has already been done. Focus on topics and not foundational areas of research

\section{- Scope: Only reviewed P2P accommodation}

- Methodology and output: Classification of studies into (eight) a-priori topics via quantitative systematic review, in contrast with topics emerging from the data. Focus on topics and not foundational areas of research

- Timespan: Articles up to December 2018; does not include the recent proliferation of research (2019-2020), which has been substantial

- Scope: Only reviewed P2P accommodation

- Timespan: Articles up to November 2018; does not include the recent proliferation of research (2019-2020), which has been substantial 


\begin{tabular}{|c|c|c|c|}
\hline $\begin{array}{l}3 \\
4 \\
5 \\
6\end{array}$ & & $\begin{array}{l}\text { destination, hosts, host-guest relationship, and } \\
\text { guest } \\
\text { Multiple appendices detail different variables } \\
\text { (e.g., sampling, methodology, theory) by cluster }\end{array}$ & \\
\hline $\begin{array}{ll}7 & \text { Sainaghi, } \\
8 & \text { Koseoglu, and } \\
9 & \text { Mehraliyev } \\
10(2020) \\
1 \\
12 \\
13 \\
14\end{array}$ & $\begin{array}{l}\text { The intellectual structure of } \\
\text { the sharing economy }\end{array}$ & $\begin{array}{l}\text { The intellectual structure of sharing economy } \\
\text { research centers around five clusters: (i) the } \\
\text { constituent elements of sharing, (ii) the sharing } \\
\text { economy and the sharing phenomenon, (iii) } \\
\text { noncommercial website platforms and the social } \\
\text { impact generated by sharing firms, (iv) } \\
\text { economic impacts, and (v) some negative } \\
\text { impacts }\end{array}$ & $\begin{array}{l}\text { - } \quad \text { Scope: Only reviewed P2P accommodation } \\
\text { Methodology and output: Used co-citation analysis only. } 99 \text { out of } \\
\text { initial sample of } 189 \text { papers used. Less emphasis on research gaps and } \\
\text { opportunities, but more on what has already been done } \\
\text { Timespan: Articles up to November } 2018 \text {; does not include the recent } \\
\text { proliferation of research (2019-2020), which has been substantial }\end{array}$ \\
\hline $\begin{array}{l}15 \text { Sainaghi, } \\
16 \text { Koseoglu, d } \\
17 \text { Angella, and } \\
18 \text { Mehraliyev } \\
19(2020) \\
26\end{array}$ & $\begin{array}{l}\text { Sharing economy: a co- } \\
\text { citation analysis }\end{array}$ & $\begin{array}{l}\text { - The intellectual structure of sharing economy } \\
\text { research centers around four clusters: economic } \\
\text { and social impacts, foundation studies rooted in } \\
\text { sociological mechanisms, authenticity and } \\
\text { disruptive innovation, and traveler motivations } \\
\text { and behavior }\end{array}$ & $\begin{array}{l}\text { - } \quad \text { Scope: Only reviewed P2P accommodation } \\
\text { Methodology and output: Used co-citation analysis only. } 79 \text { out of } \\
\text { initial sample of } 194 \text { papers used. Less emphasis on research gaps and } \\
\text { opportunities, but more on what has already been done } \\
\text { - Timespan: Articles up to March 2018; does not include the recent } \\
\text { proliferation of research (2018-2020), which has been substantial }\end{array}$ \\
\hline
\end{tabular}


Table 2. Number of publications per year by outlet

\begin{tabular}{|c|c|c|c|c|c|c|c|c|c|c|}
\hline 800 & 2012 & 2013 & 2014 & 2015 & 2016 & 2017 & 2018 & 2019 & 2020 & Total \\
\hline International Journal of Hospitality Management & & & & & 1 & 4 & 9 & 26 & 10 & 50 \\
\hline International Journal of Contemporary Hospitality Management & & & & & & 16 & 6 & 11 & 2 & 35 \\
\hline Current Issues in Tourism & & & 1 & 1 & & & 4 & 16 & 13 & 35 \\
\hline Annals of Tourism Research & & 1 & & & 2 & 4 & 1 & 10 & 9 & 27 \\
\hline Tourism Management & & & & & 2 & 2 & 4 & 8 & 10 & 26 \\
\hline International Journal of Culture, Tourism, and Hospitality Research & & & & & & 1 & 1 & 11 & 2 & 15 \\
\hline Journal of Travel Research & & & & & 1 & 1 & 1 & 6 & 5 & 14 \\
\hline Journal of Travel and Tourism Marketing & & & & & & 1 & 8 & 3 & & 12 \\
\hline Tourism Economics & & & & & & & 2 & 4 & 4 & 10 \\
\hline Tourism Management Perspectives & & & & & 1 & & 2 & 3 & 2 & 8 \\
\hline International Journal of Tourism Cities & & & & & & & & 5 & 3 & 8 \\
\hline Journal of Hospitality and Tourism Management & & & & & & & & & 7 & 7 \\
\hline Hospitality and Society & 5 & & & & & & 2 & & & 7 \\
\hline Other & & & & 1 & 2 & 4 & 11 & 20 & 16 & 54 \\
\hline Total & 5 & 1 & 1 & 2 & 9 & 33 & 51 & 123 & 83 & 308 \\
\hline
\end{tabular}


Table 3. Primary disciplinary approach adopted

\begin{tabular}{|c|c|c|c|c|c|c|c|c|c|c|}
\hline Disciplinary approach & 2012 & 2013 & 2014 & 2015 & 2016 & 2017 & 2018 & 2019 & 2020 & Total $^{\mathrm{a}}$ \\
\hline Consumer behavior & & & & 1 & 2 & 13 & 20 & 53 & 26 & $115(37.3 \%)$ \\
\hline Social psychology & 4 & & 1 & & 4 & 5 & 16 & 24 & 13 & $67(21.8 \%)$ \\
\hline Economics & & & & & 1 & 1 & 7 & 15 & 22 & $46(14.9 \%)$ \\
\hline Revenue management/pricing & & & & & & 4 & 2 & 12 & 10 & $28(9.1 \%)$ \\
\hline Social science (economics and sociology) & & & & & & 1 & 1 & 6 & 3 & 11 \\
\hline Sociology & 1 & & & & 1 & 2 & 1 & 3 & & 8 \\
\hline Organizational theory & & & & & & & 1 & 2 & 2 & 5 \\
\hline Behavioral psychology & & & & & & 2 & 1 & 2 & & 5 \\
\hline Business model & & & & & & 2 & 1 & 1 & 1 & 5 \\
\hline Behavioral economics & & & & & & 2 & & 1 & & 3 \\
\hline Sustainability & & & & & & & & 2 & & 2 \\
\hline Host behavior & & & & & & & & & 2 & 2 \\
\hline Ecology & & & & & & & & & 2 & 2 \\
\hline Linguistics & & & & & & & 1 & & & 1 \\
\hline Philosophy & & 1 & & & & & & & & 1 \\
\hline Geography & & & & & & 1 & & & & 1 \\
\hline Multiple & & & & & 2 & & - & 2 & 2 & 6 \\
\hline Total & 5 & 1 & 1 & 2 & 9 & 33 & 51 & 123 & 83 & 308 \\
\hline
\end{tabular}


Table 4. Key outcome variables by disciplinary approach

\begin{tabular}{|c|c|c|c|c|c|c|c|c|c|c|}
\hline Discipline/key outcome variable & 2012 & 2013 & 2014 & 2015 & 2016 & 2017 & 2018 & 2019 & 2020 & Total $^{\mathrm{a}}$ \\
\hline Consumer behavior/social psychology & & & & & 4 & 10 & 15 & 61 & 30 & $120(39 \%)$ \\
\hline Intention to use/re-use & & & & & & 5 & 8 & 17 & 12 & $42(13.6 \%)$ \\
\hline Satisfaction and loyalty & & & & & 2 & & 2 & 10 & 1 & 15 \\
\hline Decision to choose/book & & & & & 1 & 1 & 2 & 5 & 2 & 11 \\
\hline Review/rating & & & & & & 1 & & 6 & 3 & 10 \\
\hline Other & & & & & 1 & 3 & 3 & 23 & 12 & 42 \\
\hline Economics/revenue management & & & & & 1 & 6 & 7 & 28 & 29 & $71(23.1 \%)$ \\
\hline Revenue/performance & & & & & & 2 & 1 & 8 & 8 & 19 \\
\hline Price & & & & & & 2 & 2 & 7 & 6 & 17 \\
\hline Demand & & & & & & 2 & 3 & 1 & 4 & 10 \\
\hline Other & & & & & 1 & & 1 & 12 & 11 & 25 \\
\hline None (no specific outcome variable) & 5 & 1 & 1 & 2 & 4 & 16 & 28 & 33 & 22 & $112(36.4 \%)$ \\
\hline Other & & & & & D & 1 & 1 & 1 & 2 & 5 \\
\hline Total & 5 & 1 & 1 & 2 & 9 & 33 & 51 & 123 & 83 & 308 \\
\hline
\end{tabular}


Table 5. Theories used

\begin{tabular}{lrrrrrrrrrr}
\hline Theory & 2012 & 2013 & 2014 & 2015 & 2016 & 2017 & 2018 & 2019 & 2020 & Total $^{\mathrm{a}}$ \\
\hline A-theoretical & 3 & & 1 & 1 & 8 & 18 & 27 & 63 & 37 & $158(51.3 \%)$ \\
Hedonic pricing theory & & & & & & 1 & 1 & 5 & 2 & 9 \\
Motivational theory & & & & & & & & 1 & 5 & 6 \\
Disruptive innovation theory & & & & 1 & & 2 & 1 & 1 & 1 & 6 \\
Value co-creation & & & & & & 2 & & 1 & 1 & 4 \\
Social exchange theory & & & & & & 1 & & 3 & & 4 \\
Other & 2 & 1 & 0 & 0 & 1 & 9 & 22 & 49 & 37 & 121 \\
\hline Total & 5 & 1 & 1 & 2 & 9 & 33 & 51 & 123 & 83 & 308 \\
\hline aPercentage of total presented for key statistics
\end{tabular}

aPercentage of total presented for key statistics 
Table 6. Primary research method and data collection strategy

\begin{tabular}{|c|c|c|c|c|c|c|c|c|c|c|}
\hline Research method and data collection & 2012 & 2013 & 2014 & 2015 & 2016 & 2017 & 2018 & 2019 & 2020 & Total $^{\mathrm{a}}$ \\
\hline Quantitative & & & & 1 & 4 & 25 & 32 & 82 & 57 & $201(65.3 \%)$ \\
\hline Secondary data collection & & & & & 1 & 11 & 14 & 47 & 37 & $110(35.7 \%)$ \\
\hline Online survey & & & & 1 & 3 & 10 & 17 & 31 & 15 & $77(25 \%)$ \\
\hline Survey: traditional & & & & & & 4 & 1 & 3 & 4 & 12 \\
\hline Field experiment & & & & & & & & 1 & & 1 \\
\hline Other & & & & & & & & & 1 & 1 \\
\hline Qualitative & 4 & & & & 1 & 3 & 14 & 30 & 16 & 67 \\
\hline Interviews & & & & & & & 7 & 11 & 12 & 30 \\
\hline Secondary data collection & & & & & 1 & 3 & 2 & 12 & 2 & 20 \\
\hline Multiple-qualitative & 3 & & & & & & 5 & 4 & & 12 \\
\hline Participant observation & 1 & & & & & & & 1 & & 2 \\
\hline Netnography & & & & & & & & 1 & 1 & 2 \\
\hline Focus group & & & & & & & & & 1 & 1 \\
\hline Conceptual & & 1 & 1 & 1 & 1 & 4 & 3 & 6 & 4 & 21 \\
\hline No empirical data collection & & 1 & 1 & 1 & 1 & 4 & 3 & 6 & 4 & 21 \\
\hline Mixed & 1 & & & & 3 & 1 & 2 & 6 & 6 & 19 \\
\hline Mixed: qual/quant & 1 & & & & 3 & & 2 & 4 & 6 & 16 \\
\hline Survey: traditional & & & & & & 1 & & 1 & & 2 \\
\hline Secondary data collection & & & & & & & & 1 & & 1 \\
\hline Total & 5 & 1 & 1 & 2 & 9 & 33 & 51 & 123 & 83 & 308 \\
\hline
\end{tabular}


Table 7. Analytical method

\begin{tabular}{|c|c|c|c|c|c|c|c|c|c|c|}
\hline Analysis method & 2012 & 2013 & 2014 & 2015 & 2016 & 2017 & 2018 & 2019 & 2020 & Total $^{2}$ \\
\hline Regression & & & & & 3 & 9 & 10 & 34 & 28 & $84(27.3 \%)$ \\
\hline Content/thematic analysis & 5 & & & & 1 & 3 & 6 & 22 & 18 & $55(17.9 \%)$ \\
\hline SEM & & & & & 1 & 2 & 6 & 10 & 12 & $31(10.1 \%)$ \\
\hline Descriptive statistics & & & & 1 & & 3 & 3 & 5 & 6 & 18 \\
\hline Conceptual study (no empirical analysis) & & 1 & 1 & 1 & 1 & 4 & 2 & 3 & 3 & 16 \\
\hline PLS-SEM & & & & & & 3 & 4 & 7 & & $14(4.5 \%)$ \\
\hline ANOVA & & & & & & 2 & & 7 & 1 & 10 \\
\hline Data mining & & & & & & 2 & 2 & 4 & & 8 \\
\hline Grounded theory & & & & & & & 3 & 3 & 1 & 7 \\
\hline Specific methods (e.g., frame analysis) & & & & & & & 1 & 3 & 3 & 7 \\
\hline Interpretive/discursive/semantic analysis & & & & & & & 3 & 3 & & 6 \\
\hline Multivariate techniques & & & & & & & 2 & 2 & 2 & 6 \\
\hline Basic inferential statistics & & & & & & 1 & & 3 & & 4 \\
\hline fsQCA & & & & & & & 1 & 1 & & 3 \\
\hline Case study analysis & & & & & & & & 3 & & 3 \\
\hline Latent class modeling & & & & & & 1 & 1 & 1 & & 3 \\
\hline Time-series analysis & & & & & & & & & 1 & 1 \\
\hline Multiple & & & & & 3 & 2 & 7 & 12 & 8 & 32 \\
\hline Total & 5 & 1 & 1 & 2 & 9 & 33 & 51 & 123 & 83 & 308 \\
\hline
\end{tabular}

aPercentage of total presented for key statistics 
Table 8. Stakeholder perspective

\begin{tabular}{|c|c|c|c|c|c|c|c|c|c|c|}
\hline Stakeholder & 2012 & 2013 & 2014 & 2015 & 2016 & 2017 & 2018 & 2019 & 2020 & Total $^{\mathrm{a}}$ \\
\hline Guest/customer & & & & 1 & 4 & 16 & 21 & 41 & 12 & $95(30.8 \%)$ \\
\hline Platform & & & & & & 4 & 7 & 29 & 13 & 53 \\
\hline Host/supplier & & & & & & 2 & 5 & 5 & 8 & 20 \\
\hline Residents & & & & & & & 1 & 6 & 8 & 15 \\
\hline Sharing economy (whole) & & 1 & 1 & 1 & 1 & 2 & 3 & 3 & 1 & 14 \\
\hline Hotel industry & & & & & 1 & & & 5 & 6 & 12 \\
\hline Destination & & & & & & 1 & & 8 & 2 & 11 \\
\hline Academia & & & & & & & & & 3 & 3 \\
\hline Tourism industry & & & & & 1 & & & 1 & 1 & 3 \\
\hline Restaurant industry & & & & & & & & & 1 & 1 \\
\hline Multiple & 4 & & & 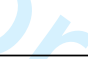 & 2 & 8 & 14 & 25 & 28 & 81 \\
\hline Total & 5 & 1 & 1 & 2 & 9 & 33 & 51 & 123 & 83 & 308 \\
\hline
\end{tabular}

aPercentage of total presented for key statistics 
Table 9. Focal sharing economy sector

\begin{tabular}{|c|c|c|c|c|c|c|c|c|c|c|}
\hline Sharing economy sector & 2012 & 2013 & 2014 & 2015 & 2016 & 2017 & 2018 & 2019 & 2020 & Total $^{\mathrm{a}}$ \\
\hline $\mathrm{P} 2 \mathrm{P}$ accommodation & 5 & 1 & 1 & 2 & 8 & 27 & 46 & $113(36.7 \%)$ & 77 & $280(90.9 \%)$ \\
\hline Airbnb & & & & 1 & 4 & 18 & 28 & 88 & 54 & $193(62.7 \%)$ \\
\hline P2P accommodation (Overall) & & & & & 2 & 5 & 11 & 24 & 22 & 64 \\
\hline Couchsurfing & 5 & 1 & & & 2 & 1 & 6 & & & 15 \\
\hline Xiaozhu & & & & & & 1 & 1 & 1 & & 3 \\
\hline Home-swapping & & & 1 & 1 & & & & & & 2 \\
\hline VRBO & & & & & & 2 & & & & 2 \\
\hline Tujia & & & & & & & & & 1 & 1 \\
\hline Transportation & & & & & & 2 & 2 & 5 & 3 & 12 \\
\hline Transportation (Overall) & & & & & & 1 & 2 & 4 & 3 & 10 \\
\hline Uber & & & & & & 1 & & 1 & & 2 \\
\hline Sharing Economy (Whole) & & & & & 1 & 4 & 1 & 2 & 1 & 9 \\
\hline $\mathrm{P} 2 \mathrm{P}$ experiences & & & & & & & 1 & 1 & 1 & 3 \\
\hline Food and beverage & & & & & & & 1 & 2 & 1 & 4 \\
\hline Meal-sharing & & & & & & & & & 1 & 1 \\
\hline Food delivery & & & & & & & & 1 & & 1 \\
\hline Dining & & & & & & & & 1 & & 1 \\
\hline $\mathrm{P} 2 \mathrm{P}$ events & & & & & & & 1 & & & 1 \\
\hline Total & 5 & 1 & 1 & 2 & 9 & 33 & 51 & 123 & 83 & 308 \\
\hline
\end{tabular}


Table 10. Future research recommendations for the sharing economy

\section{Thematic recommendations for future research using MLP}

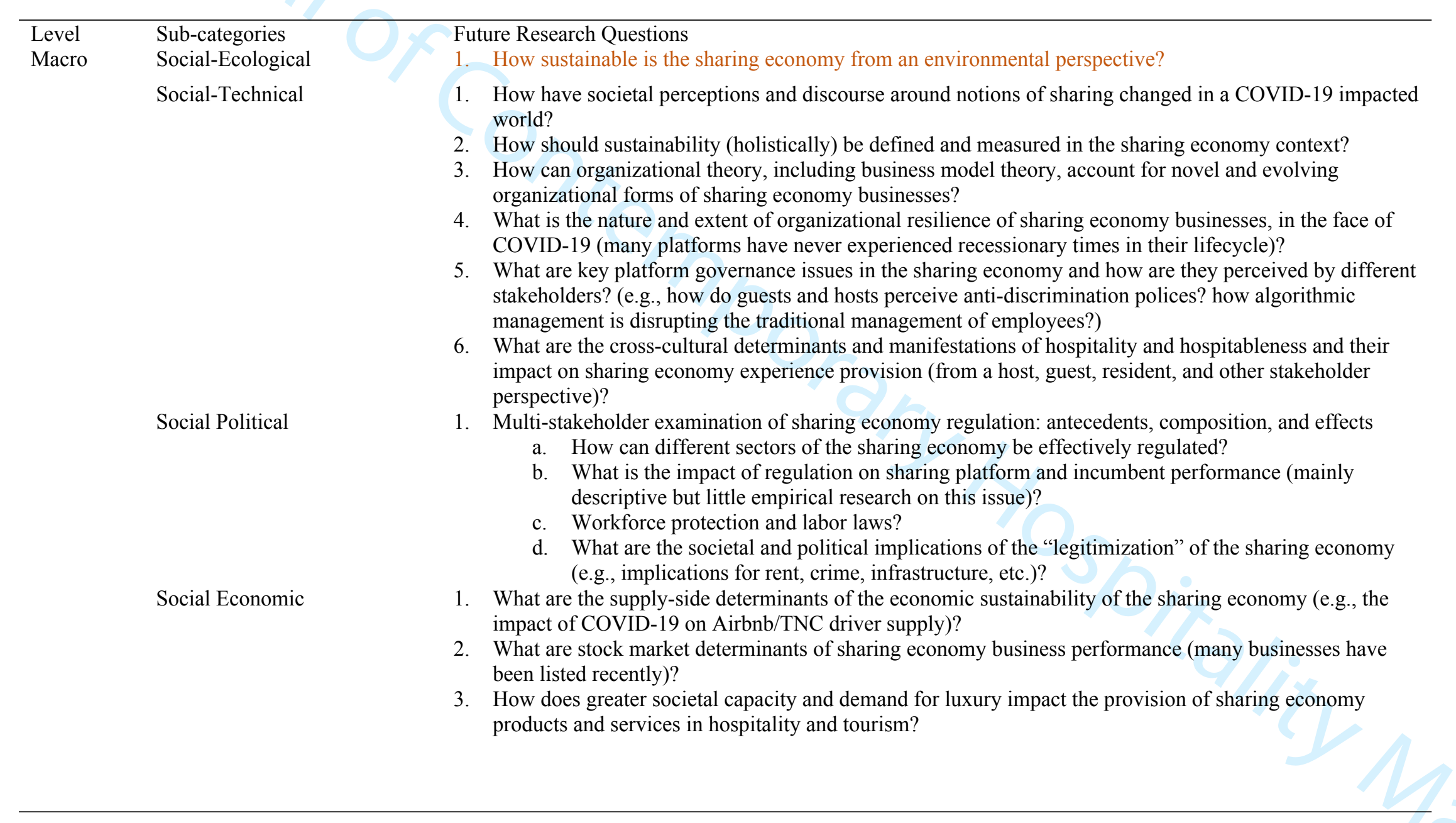




\section{Meso Platforms 1. Airbnb: \\ a. How does consumer behavior and experience differ different types of Airbnb accommodation: private, shared, and entire homes (mainly used as a dummy variable in extant research)? \\ b. What is the nature of the experience across different Airbnb brands (e.g., Airbnb Plus, Airbnb Luxe)? \\ c. How effective is Airbnb as a distribution platform for hotels and other types of traditional accommodation? What are the implications for online travel agents and accommodation suppliers? \\ d. How does the Airbnb experience compare with the stakeholder experience of other accommodation platforms (e.g., VRBO)? \\ e. What are the reasons for the failure of Airbnb's brand extensions (e.g., Niido by Airbnb)?}

2. What are the dynamics of niche sharing economy platforms targeting consumer microsegments (e.g., Mister $B \& B$ for the gay traveler; Third Home for affluent second-home exchange and rentals)?

3. Branding of sharing economy platforms:

a. What are the determinants of sharing economy brand equity and how does it differ from traditional B2C and B2B brands (e.g., multi-sided platforms are likely to have multiple sources of brand equity)?

b. How do stakeholders' (e.g., customer and host) brand experiences over time (longitudinally) impact their perception of brand equity?

4. How does digital marketing in "tech-first" sharing economy platforms - user experience design, integrated marketing communications, content marketing, etc.- - differ from traditional incumbents?

5. How do culturally-endemic sharing economy platforms (e.g., Grab and GoJek in Indonesia) differ from global players like Airbnb and Uber?

6. How do sharing economy businesses form strategic alliances (e.g., Airbnb working with Qantas Airlines for customers to gain Qantas points)?

Hotels

1. How do consumers choose between sharing economy and hotel/accommodation alternatives (e.g., using choice-based methodologies vs. predominantly inference-based methodologies)? How has COVID-19 altered this choice dynamic?

2. How does the supply of all short-term rentals in a destination on hotel performance (nearly all studies include Airbnb supply only)?

3. How does the hotel-homesharing platform (e.g., Marriott Homes \& Villas International) create customer value? What are customer expectations and experience of such platforms?

4. How do hoteliers perceive they can successfully compete against and/or co-opt sharing economy businesses?

Transportation

1. What is the role of safety in P2P transportation experiences from a customer perspective? How does it impact experience dynamics and brand perceptions (in light on several high-profile incidents; previously examined mainly in an accommodation context)?

2. What is the impact of regulation of P2P transportation for customer and stakeholder welfare (e.g., consumer welfare vs. traditional taxi industry)? 


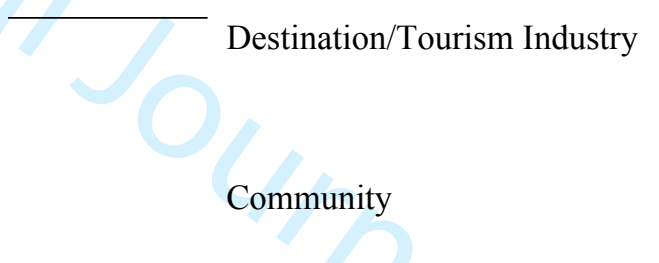

1. How do sharing economy platforms contribute to the overall tourism mix and sustainability of the tourism industry in a destination?

2. What is the role of the sharing economy in overtourism at destinations?

3. How will destinations respond to the presence of sharing economy visitors during and after COVID-19?

1. How does the sharing economy impact the culture of host residents?

2. How will locals respond to sharing economy-induced visitation in their communities during and after COVID-19?

1. How to experience dimensions impact the selection of sharing economy providers (e.g., does a customer choose a specific experience due to high perceived authenticity?) (most extant research is on post-hoc experience evaluation of the experience)?

2. What are important dimensions of the customer experience of non-accommodation sectors of the sharing economy (e.g., meal-sharing, transportation, restaurants, tours, events)?

a. What are the different segments of "experience seekers" outside of the accommodation

$$
\text { experience? }
$$

3. Do P2P experiences across sectors have additive and/or interactive effects on customer outcomes; e.g., how does a customer who stays at an Airbnb accommodation and partakes in an Airbnb experience on the same trip to a destination perceive brand Airbnb and the destination experience?

4. What is the customer experience of new, online sharing economy experiences-Airbnb Online Experiences, Amazon Explore? Are the key dimensions of online experiences different from those of offline experiences?

5. How does the customer's total experience of a destination via the "informal", sharing economy compare to the experiences of customers in the formal (traditional) economy?

6. How does the customer experience compare across a peer-hosted vs. a professionally hosted home (i.e., what is the impact of platform "professionalization" on experience provision)?

7. Changing consumer behavior in the face of COVID-19: How has role of constructs like trust and safety changed in customer decision-making and experience evaluation during COVID-19?

8. What are the attitudes, preferences, experiences, and behaviors of minority customers in the sharing economy (e.g., black, Hispanic, female, disabled, etc.).

Provider/Supplier

9. What needs of business customers does the sharing economy fill and how (e.g., Airbnb for Business; Uber Business)?

1. What are the different dimensions of host behavior in the sharing economy: e.g., how do hosts make pricing decisions, hosts' service recovery orientation and behavior?

2. How do "prosumers"-individuals who are both consumers and suppliers on sharing economy platforms - create and perceive brand experiences (some initial research in the Couchsurfing context)?

3. How do hosts transition to providing online P2P experiences (e.g., Airbnb Online Experiences, Amazon Explore)?

4. How can host segments be matched with customer segments to optimize host-consumer fit in the sharing economy? 
Other Stakeholders

5. How do hosts review customers in the sharing economy (most extant research focuses on customer reviews only)?

a. How do host reviews compare with guest reviews and does it help identify sources and nature of review "positivity bias" in the sharing economy (an issue identified in previous studies)?

1. What role do third-party property management companies play in the accommodation sector?

\section{Methodology recommendations for future research on the sharing economy}

\begin{tabular}{|c|c|}
\hline Research Approaches and Methods & $\begin{array}{l}\text { 1. Combine the use of primary and secondary data sources to examine a topic holistically (e.g., examine } \\
\text { hosts' revenue management practices using secondary data and primary interview data) } \\
\text { a. Using small data (e.g., survey) for theory development and big-data (e.g., data mining) for theory } \\
\text { validation (or vice-versa) } \\
\text { 2. Big data approaches that incorporate geospatial parameters (e.g., geo-tagged social media data) to } \\
\text { examine the interaction between geography and the sharing economy } \\
\text { 3. Using platforms other than MTurk for data collection } \\
\text { 4. More qualitative and mixed-methods research (e.g., autoethnography to produce rich and subjective data) } \\
\text { 5. Collection and analysis of alternative forms of "rich" data (images, video, journals, etc.) (see, for } \\
\text { example, Payyanadan and Lee's (2018) study of the ridesharing needs of older adults). } \\
\text { 6. Using dependent variables beyond those typically used in consumer behavior (e.g., intention to re-use) } \\
\text { and economics/revenue management domains (e.g., OCC, RevPAR). Examples of alternative dependent } \\
\text { variables include frequency of use, share of wallet, willingness to pay, etc. } \\
\text { 7. Need for more in-situ research design. Extant research driven mainly by post-hoc data collection and } \\
\text { analysis: higher potential for recall biases, limited ability to capture interactional elements of the sharing } \\
\text { economy (e.g., host-guest interaction in-situ) and limited ability to capture actual behavior (vs. behavioral } \\
\text { intentions) } \\
\text { Use of longitudinal designs to capture dynamic elements of sharing economy phenomena (e.g., how is a } \\
\text { customer's perception of a sharing economy brand formed over time, via multiple brand experiences?) } \\
\text { 9. Experimental design that allow testing of specific, directional, and causal hypotheses }\end{array}$ \\
\hline Sampling & $\begin{array}{l}\text { 1. Sample definition is often vague or not provided } \\
\text { 2. Use of random and in-person samples over convenience/self-selected and online samples for survey } \\
\text { research } \\
\text { 3. Use of alternative sources of data for "review"-based studies (e.g., Airbnbhell.com and other Airbnb host } \\
\text { forums) }\end{array}$ \\
\hline Validity and Reliability & $\begin{array}{l}\text { 1. Need for triangulation of findings using multiple methods of data collection and analysis, or multiple } \\
\text { samples (exploratory and validation) in the same study } \\
\text { 2. Survey research: Control for method biases like social desirability }\end{array}$ \\
\hline
\end{tabular}


3. Secondary data: accounting for time lag in econometric models (e.g., listing description changes at time t1 to impact listing performance at time t2). Currently, there is an excessive use of cross-sectional designs to infer causality

4. Need for cross-cultural comparison and validation of study findings to move beyond a largely "Western" perspective of the sharing economy.

a. Extant cross-cultural collaborations still rely on largely Western datasets

b. More developing country perspectives of the sharing economy (e.g., the nature of trust in sharing is different in Morocco than in Western Europe with its better established legal and economic systems)

5. SEM

a. Need to test for alternative theoretically-driven models in the same study, as opposed to developing and testing one model only

b. Provide justification for use of PLS-SEM over covariance-based SEM. Often, the former is used even when studies are not exploratory in nature and/or use previously validated constructs (in which case, covariance-based SEM should be used) 


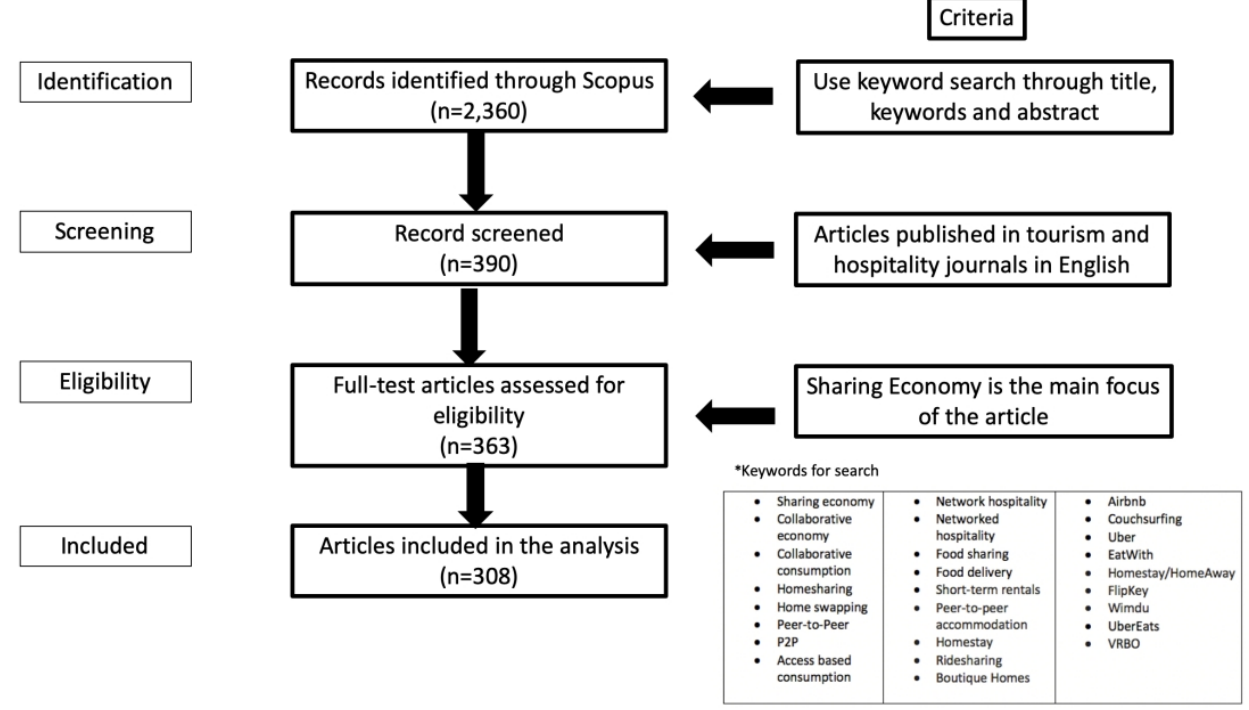

Figure 1. A PRISMA flowchart of sharing economy research in hospitality and tourism 


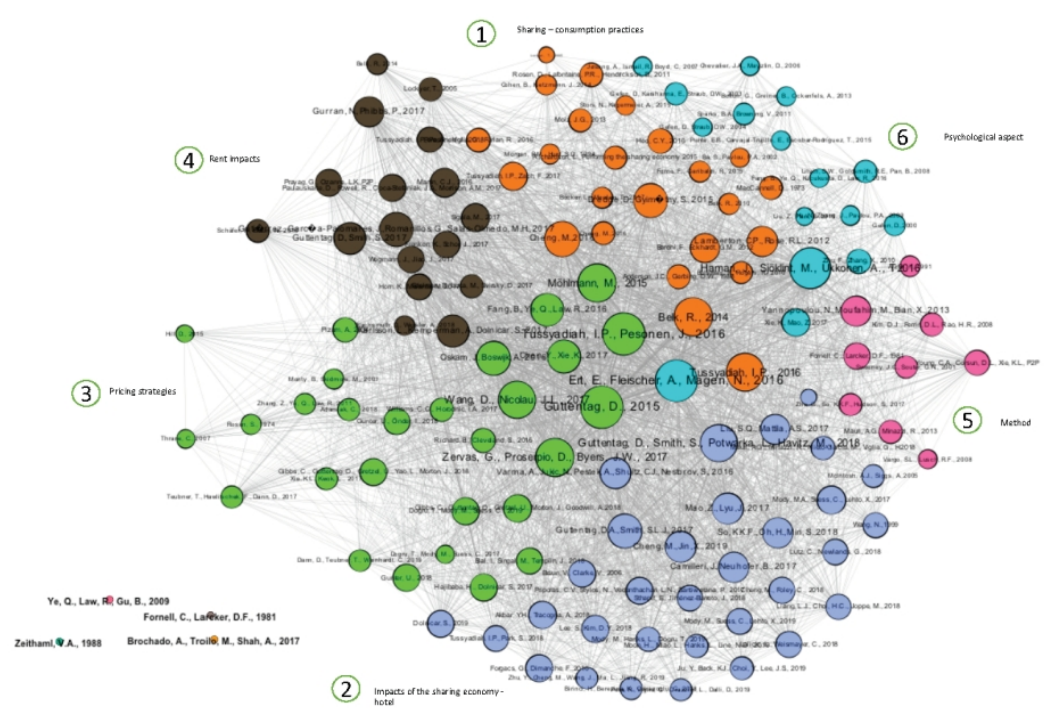

Figure 2. Network-based intellectual foundations of sharing economy research 


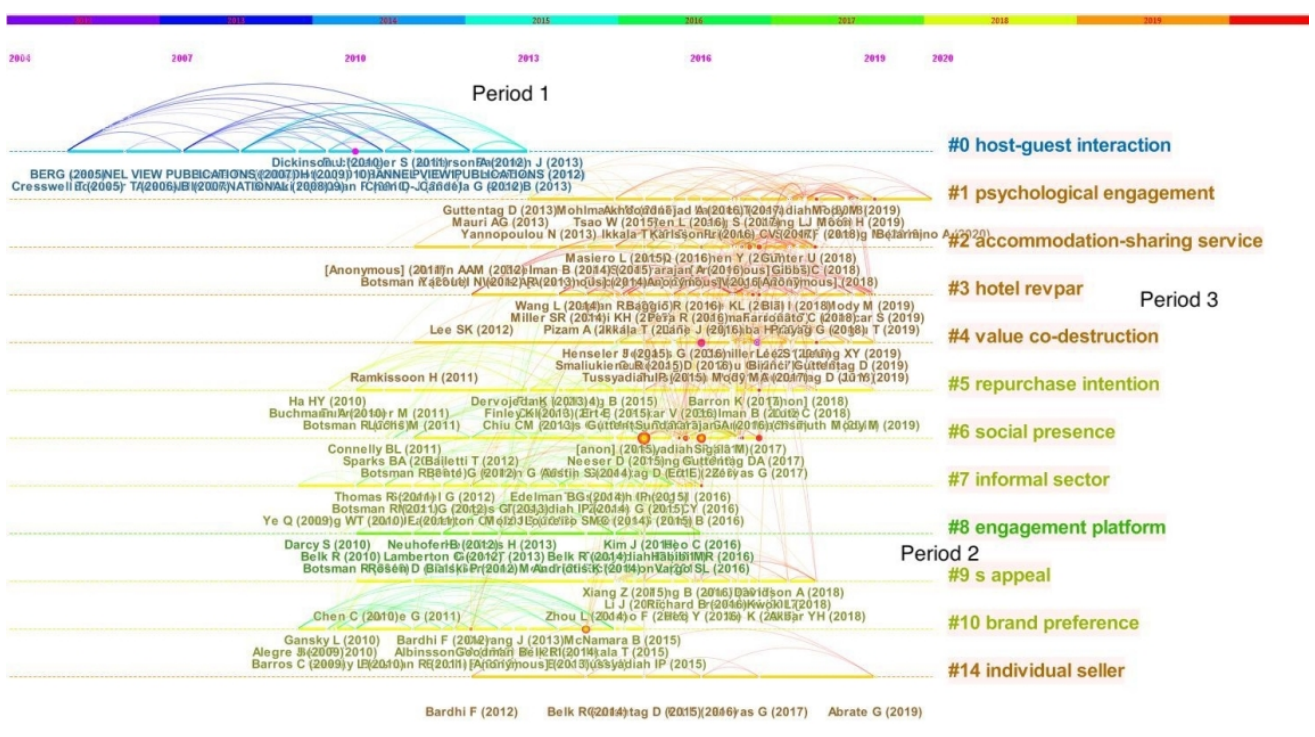

Figure 3. Co-citation cluster* by year (grouped by period)

*The cluster names are different from Figure 2; however, they reflect the intellectual foundations at a lower order

$312 \times 174 \mathrm{~mm}(120 \times 120 \mathrm{DPI})$ 
Figure 4. Results of thematic content analysis 
Figure 5. Continent of author institution affiliation 


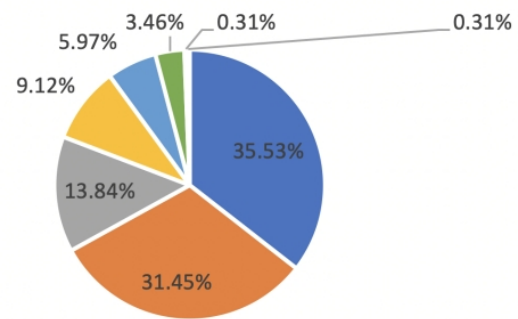

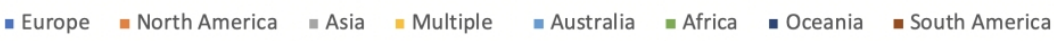

Figure 6. Continent of research setting (for empirical studies only) 